Cite this: Nanoscale, 2014, 6, 5532

\title{
Colloidal nickel/gallium nanoalloys obtained from organometallic precursors in conventional organic solvents and in ionic liquids: noble-metal-free alkyne semihydrogenation catalysts $\dagger$
}

Kai Schütte, ${ }^{a}$ Adinarayana Doddi, ${ }^{\mathrm{b}}$ Clarissa Kroll, ${ }^{\mathrm{b}}$ Hajo Meyer, ${ }^{a}$ Christian Wiktor, ${ }^{\mathrm{bc}}$ Christian Gemel, ${ }^{\text {b }}$ Gustaaf van Tendeloo, ${ }^{\mathrm{c}}$ Roland A. Fischer ${ }^{\star b}$ and Christoph Janiak ${ }^{\star a}$

Efforts to replace noble-metal catalysts by low-cost alternatives are of constant interest. The organometallic, non-aqueous wet-chemical synthesis of various hitherto unknown nanocrystalline $\mathrm{Ni} / \mathrm{Ga}$ intermetallic materials and the use of NiGa for the selective semihydrogenation of alkynes to alkenes are reported. Thermal co-hydrogenolysis of the all-hydrocarbon precursors $\left[\mathrm{Ni}(\mathrm{COD})_{2}\right](\mathrm{COD}=1,5$ cyclooctadiene) and $\mathrm{GaCp} *$ (Cp* = pentamethylcyclopentadienyl) in high-boiling organic solvents mesitylene and $n$-decane in molar ratios of $1: 1,2: 3$ and $3: 1$ yields the nano-crystalline powder materials of the over-all compositions $\mathrm{NiGa}, \mathrm{Ni}_{2} \mathrm{Ga}_{3}$ and $\mathrm{Ni}_{3} \mathrm{Ga}$, respectively. Microwave induced copyrolysis of the same precursors without additional hydrogen in the ionic liquid [BMIm] $\left.\mathrm{BF}_{4}\right]\left(\mathrm{BMIm}_{\mathrm{l}}=1-\right.$ butyl-3-methyl-imidazolium) selectively yields the intermetallic phases $\mathrm{NiGa}$ and $\mathrm{Ni}_{3} \mathrm{Ga}$ from the respective 1:1 and 3:1 molar ratios of the precursors. The obtained materials are characterized by transmission electron microscopy (TEM), energy dispersive $X$-ray spectroscopy (EDX), IR, powder X-ray diffraction (PXRD) and atomic absorption spectroscopy (AAS). The single-source precursor $\left[\mathrm{Ni}(\mathrm{GaCp} *)\left(\mathrm{PMe}_{3}\right)_{3}\right]$ with a fixed $\mathrm{Ni}$ : Ga stoichiometry of $1: 1$ was employed as well. In comparison with the co-hydrogenolytic dual precursor source approach it turned out to be less practical due to inefficient nickel incorporation caused by the parasitic formation of stable $\left[\mathrm{Ni}\left(\mathrm{PMe}_{3}\right)_{4}\right]$. The use of ionic liquid $[\mathrm{BMIm}]\left[\mathrm{BF}_{4}\right]$ as a non-conventional solvent to control the reaction and stabilize the nanoparticles proved to be particularly advantageous and stable colloids of the nanoalloys $\mathrm{NiGa}$ and $\mathrm{Ni}_{3} \mathrm{Ga}$ were obtained. A phase-selective $\mathrm{Ni} / \mathrm{Ga}$ colloid synthesis in conventional solvents and in the presence of surfactants such as hexadecylamine (HDA) was not feasible due to the undesired reactivity of HDA with $\mathrm{GaCp} *$ leading to inefficient gallium incorporation. Recyclable $\mathrm{NiGa}$ nanoparticles selectively semihydrogenate 1-octyne and diphenylacetylene (tolan) to 1-octene and diphenylethylene, respectively, with a yield of about $90 \%$ and selectivities of up to 94 and $87 \%$. Ni-NPs yield alkanes with a selectivity of 97 or $78 \%$, respectively, under the same conditions.

Received 7th January 2014 Accepted 4th March 2014

DOI: 10.1039/c4nr00111g

www.rsc.org/nanoscale

\section{Introduction}

The properties of metals can be fine-tuned by alloying., ${ }^{1,2}$ Bimetallic nanoalloys are particularly interesting for applications in colloidal and heterogeneous catalysis. ${ }^{2-4}$ Bottom-up synthesis of such nanoalloys by soft, wet-chemical methods is of particular relevance in this respect. ${ }^{5-7}$ Most studies on bimetallic systems are focussed on combinations of transition metals, typically involving noble metals which can easily be obtained by reduction from salt-like molecular precursors. Far less results are published on nanoalloys with electropositive Zn, $\mathrm{Al}$, or $\mathrm{Ga}$ as components. ${ }^{2,3}$ For example, Armbrüster et al. described the promising properties of $\mathrm{PdGa}, \mathrm{Pd}_{2} \mathrm{Ga}, \mathrm{Pd}_{3} \mathrm{Ga}_{7}$ (ref. 8) and $\mathrm{Fe}_{4} \mathrm{Al}_{13}$ (ref. 9) for alkyne semihydrogenation to alkenes instead of alkanes. Bridier et al. reported ternary 
$\mathrm{Cu}-\mathrm{Ni}$-Fe catalysts for semihydrogenation of propyne to propene with near $100 \%$ selectivity. ${ }^{10}$ Selective (semi-)hydrogenation of alkynes to alkenes is of industrial and scientific interest, e.g., to remove catalyst-poisoning acetylene traces from ethylene feeds. ${ }^{11}$ Heterogeneous colloidal semihydrogenation catalysts typically contain noble metals ${ }^{12}$ such as $\mathrm{Pd},{ }^{13,14} \mathrm{Pt},{ }^{15} \mathrm{Ru},{ }^{16} \mathrm{Rh}^{17}$ and $\mathrm{Au} .{ }^{18}$ The usually high selectivity of semihydrogenation is still not understood completely, ${ }^{13}$ but it is clear that total hydrogenation requires larger active sites than semihydrogenation ${ }^{19}$ according to the site-isolation concept. ${ }^{20}$ Hence a careful and perhaps fortuitous catalyst design involving alloying, Pd-C-phase formation, ${ }^{21}$ and addition of promoters is necessary to achieve the desired semihydrogenation selectivity of the noble metal nano-catalysts together with high activity and catalyst stability. Compared to these established catalysts it seems that the Hume-Rothery type intermetallic compounds of type B metals (i.e. groups 2, 12 and 13) with low-cost transition metals are very promising novel materials in place of expensive noble-metal catalysts.

Previously we reported a non-aqueous organometallic synthesis of nano-brass $\left(\alpha / \beta-\mathrm{CuZn}, \gamma-\mathrm{Cu}_{3} \mathrm{Zn}\right)$ by the co-hydrogenolysis of $\left[\mathrm{CpCu}\left(\mathrm{PMe}_{3}\right)\right]$ and $\left[\mathrm{ZnCp}_{2}{ }_{2}\right]\left(\mathrm{Cp}^{*}=\right.$ pentamethylcyclopentadienyl) or the co-decomposition of $\mathrm{Cu}$ - and $\mathrm{Zn}$ amidinates $\left\{\left[\mathrm{Me}\left(\mathrm{C}\left(\mathrm{N}^{\mathrm{i} P r}\right)_{2}\right)\right] \mathrm{Cu}\right\}_{2}$ and $\left[\mathrm{Me}\left(\mathrm{C}\left(\mathrm{N}^{\mathrm{i}} \mathrm{Pr}\right)_{2}\right)\right]_{2} \mathrm{Zn}$ as metal sources. This synthesis concept was used to prepare $\mathrm{Cu} / \mathrm{ZnO}$ colloidal catalysts for methanol synthesis from $\mathrm{CO} / \mathrm{CO}_{2} / \mathrm{H}_{2} \cdot{ }^{22,23}$ Our investigations of the related group-13 organometallic precursor chemistry showed that the low-valent $\left[\left(\mathrm{AlCp}^{*}\right)_{4}\right]$ and the related $\mathrm{GaCp}^{*}$ are valuable sources to obtain the intermetallic Hume-Rothery type nanoalloys of $\mathrm{Co} / \mathrm{Al}, \mathrm{Ni} / \mathrm{Al}$ and $\mathrm{Cu} / \mathrm{Al}$ by co-hydrogenolysis of the corresponding transition metal precursors. ${ }^{24}$ Soft chemical synthesis in organic solvents from organometallic complexes is a means of access to chemical nanometallurgy and allows preparation of metals and alloys in the nanometer scale regime.,

Herein we present our results on the corresponding soft, wetchemical synthesis of, to the best of our knowledge, hitherto unknown Ni/Ga nanoalloys using the individual metal-olefin precursors, $\left[\mathrm{Ni}(\mathrm{COD})_{2}\right]$ (COD = 1,5-cyclooctadiene) and GaCp* in appropriate ratios. We have also explored the hydrogenolysis of two single-source precursors with fixed $\mathrm{Ni}$ : Ga stoichiometry, $\left[\mathrm{Ni}\left(\mathrm{GaCp}^{*}\right)\left(\mathrm{PMe}_{3}\right)_{3}\right]$ and $\left[\mathrm{Ni}\left(\mathrm{GaCp}^{*}\right)_{3}\left(\mathrm{PCy}_{3}\right)\right]$. In addition we compared this hydrogenolytic $\mathrm{Ni} / \mathrm{Ga}$ nanoalloy synthesis in conventional organic solvents (e.g. mesitylene) with the synthesis in ionic liquids (ILs) using the same precursors, but without the need for additional hydrogen. ILs are well known for their unique properties for reaction control and for inherent stabilization of metal nanoparticle ${ }^{25}$ which were prepared from metal salts, ${ }^{26-29}$ organometallic metal complexes ${ }^{30,31}$ and metal carbonyls. $^{32,33}$

\section{Nickel-gallium intermetallics}

Group-13 metals (Al, Ga and $\mathrm{In}$ ) readily form a number of different intermetallic compounds with nickel. ${ }^{34}$ In the Ni-Ga system nine phases were characterized, $\mathrm{Ni}_{3} \mathrm{Ga}, \mathrm{Ni}_{5} \mathrm{Ga}_{3}, \mathrm{Ni}_{3} \mathrm{Ga}_{2}$ (HT), $\mathrm{Ni}_{3} \mathrm{Ga}_{2}$ (LT), NiGa, $\mathrm{Ni}_{3} \mathrm{Ga}_{4}, \mathrm{Ni}_{2} \mathrm{Ga}_{3}, \mathrm{Ni}_{3} \mathrm{Ga}_{7}$ and $\mathrm{NiGa}_{5}$ (the latter two were previously believed to be $\mathrm{NiGa}_{4}$ ) (Fig. S1 in the ESI $\dagger$ ). ${ }^{35}$ The NiGa phase melts congruently at $1220{ }^{\circ} \mathrm{C} .{ }^{33}$ The ternary phase $\mathrm{Ni}-\mathrm{Mg}-\mathrm{Ga}$ is of interest as a ferromagnetic shapememory alloy also in nanoparticular form. ${ }^{36}$ In general, nickelgallium intermetallic phases and compounds are typically prepared by metallurgical processes, such as arc-melting followed by annealing at high temperatures for several weeks. Individual metals of high purity or the corresponding reducable metal salts serve as metal sources. ${ }^{37}$ However, these procedures and precursors are neither suited for obtaining nanoalloy particles with much size control nor for free-standing (i.e. not agglomerated) nanoparticles dispersed in organic solvents (i.e. nanoalloy colloids). ${ }^{6,38}$

Therefore, we compare here the synthesis of $\mathrm{Ni}_{x} \mathrm{Ga}_{y}$ nanoalloy particles from organometallic precursors $\left[\mathrm{Ni}(\mathrm{COD})_{2}\right]$ and $\mathrm{GaCp} *$ or the single-source precursor $\left[\mathrm{Ni}\left(\mathrm{GaCp}^{*}\right)\left(\mathrm{PMe}_{3}\right)_{3}\right]$ under different conditions. The phase NiGa is shown to be an effective catalyst for the semihydrogenation of alkynes.

\section{Results and discussion}

1. Nanocrystalline $\mathrm{NiGa}, \mathrm{Ni}_{2} \mathrm{Ga}_{3}$ and $\mathrm{Ni}_{3} \mathrm{Ga}$ powder samples by co-hydrogenolysis of $\left[\mathrm{Ni}(\mathrm{COD})_{2}\right]$ and $\mathrm{GaCp}^{*}$ in mesitylene

Co-hydrogenolysis of $\mathrm{GaCp}^{*}$ and $\left[\mathrm{Ni}(\mathrm{COD})_{2}\right]$ in various molar ratios in mesitylene under 4 bar $\mathrm{H}_{2}$ pressure at $150{ }^{\circ} \mathrm{C}$ in the absence of any additional surfactants leads to immediate formation of a dark-red to brown solution.

The color gradually darkens and finally a black precipitate with a colorless (NP1 and NP3) or brown (NP2) supernatant is formed (Scheme 1). The obtained insoluble products were characterized by means of powder X-ray diffraction (PXRD), bright-field transmission electron microscopy (BF-TEM), highresolution TEM (HR-TEM), energy-dispersive X-ray spectroscopy (EDX), and atomic absorption spectroscopy (AAS) after digestion of a fraction of the respective sample. Fourier transform infrared spectroscopy (FTIR) proves the absence of any stabilizing organic moieties or hydrocarbon impurities. The PXRD patterns (Fig. 1) provide evidence for the formation of NiGa (NP1), $\mathrm{Ni}_{2} \mathrm{Ga}_{3}$ (NP2) and $\mathrm{Ni}_{3} \mathrm{Ga}$ (NP3) which match the employed stoichiometric ratios of the reactants (Scheme 1). High resolution TEM images of all three samples (Fig. 1) confirm that the obtained materials are indeed nano-crystalline. NP1 and NP3 were proven to be NiGa and $\mathrm{Ni}_{3} \mathrm{Ga}$ by indexing Fourier analyses of HR-TEM images of the corresponding samples (Fast Fourier Transformation, FFT, images of NP1 and NP3 in Fig. 1b are shown directly below in Fig. 1c). A high degree of agglomeration is observed, due to the absence of

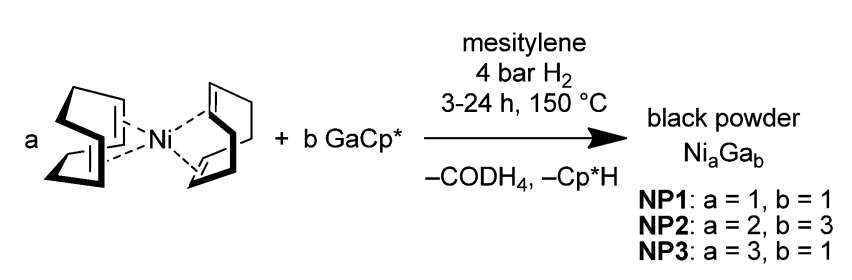

Scheme 1 Co-hydrogenolysis of $\left[\mathrm{Ni}(\mathrm{COD})_{2}\right]$ and $\mathrm{GaCp} *$ in mesitylene. 
NP 1
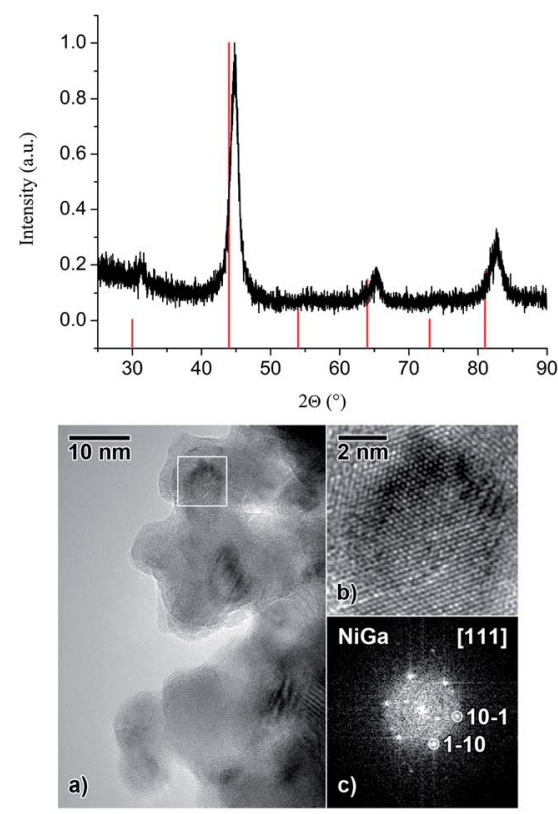

NP 2
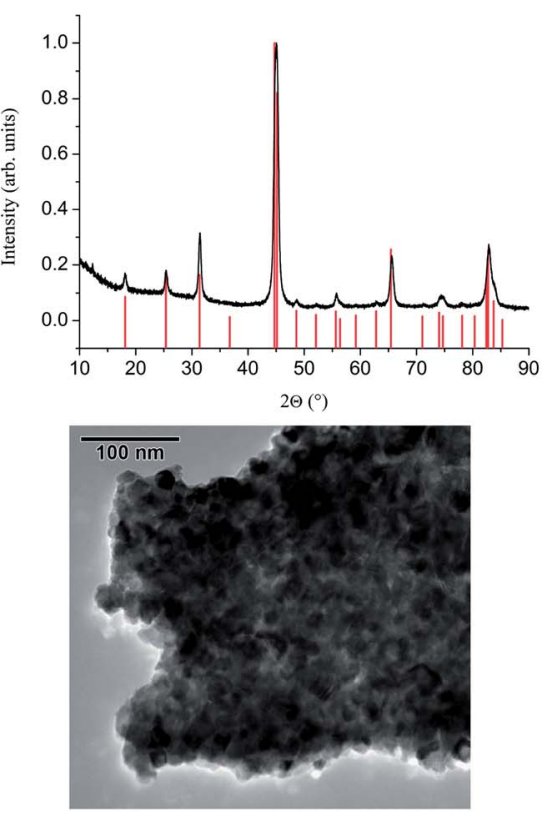

NP 3
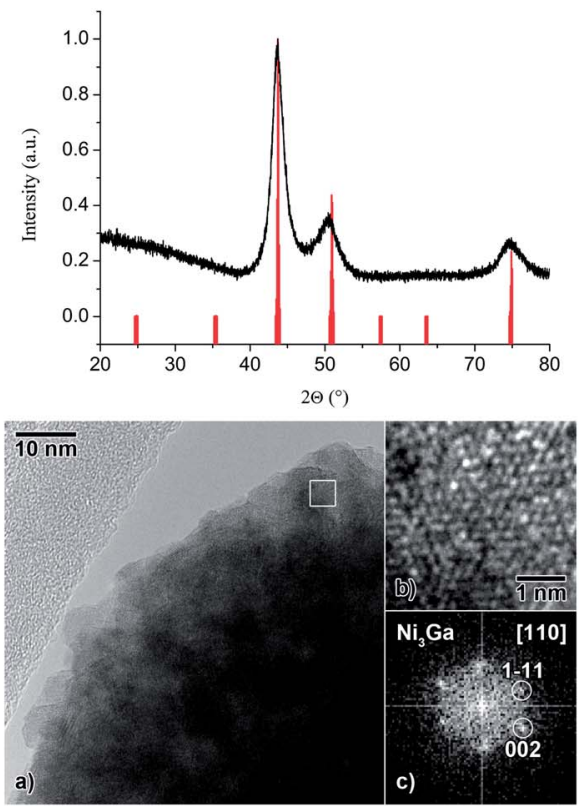

Fig. 1 PXRD, HR-TEM images and magnifications and FFTs of the respective areas marked by white squares of nanocrystalline Ni/Ga powder samples NP1, NP2 and NP3. Reference data for PXRD and FFT indexation assignments were taken from ICSD no. 103854 (NiGa), 103860 (Ni $2 \mathrm{Ga}_{3}$ ) and $103856\left(\mathrm{Ni}_{3} \mathrm{Ga}\right)$.

any agents that could stabilize individual nanoparticles and their inherent superparamagnetic properties. EDX analyses (up to $\pm 4 \%$ rel. error) of different agglomerates of NP1 and NP3 confirm the formation of rather pure $\mathrm{NiGa}$ and $\mathrm{Ni}_{3} \mathrm{Ga}$. NP2 was found to be rather impure $\mathrm{Ni}_{2} \mathrm{Ga}_{3}$. Although the PXRD (Fig. 1) shows only reflections of the $\mathrm{Ni}_{2} \mathrm{Ga}_{3}$ phase, EDX spectra of different agglomerates of NP2 yield different $\mathrm{Ni} / \mathrm{Ga}$ ratios (Table S1 and Fig. S3-S5 in the ESI $\dagger$ ). According to AAS reference data, the Ni and Ga molar ratios of the bulk samples are rather close to the expected values from TEM-EDX and correspond to the analytical compositions $\mathrm{Ni}_{1} \mathrm{Ga}_{1.07}$ (NP1), $\mathrm{Ni}_{2} \mathrm{Ga}_{3.08}$ (NP2) and $\mathrm{Ni}_{2.79} \mathrm{Ga}$ (NP3). If the overall composition derived from AAS is compared to the composition of individual agglomerated nanoparticles derived by EDX it is apparent that there are impurities of amorphous or hardly crystalline Ni and Ga in NP2. Notably, a reproducible shift to somewhat larger values of $2 \theta$ in the powder XRD pattern of NP1 (assigned to the NiGa phase), suggesting significant contraction of the lattice parameters, is observed (Fig. 1). Such shifts in PXRD patterns are not uncommon for nanoparticles. A number of effects can be considered including a wide range of stoichiometric compositions, partly inhomogeneous element distribution, defects such as stacking and twin faults and nanosized crystalline domains being much smaller than the bulk reference material causing lattice contraction or expansion and strain..$^{39}$

However, the shifts in the reflections for NP1 are too high to be caused by a mere size effect of the crystalline domains. For NP2 EDX shows a rather impure sample (see above). For NP3 the width of the reflections is unreasonably large to be caused by small crystallites. Because of this and the high degree of agglomeration in the TEM images we conclude that calculation of the particle sizes for NP1-3 from the PXRD patterns is not reasonable and will therefore not be presented here.

\section{Hydrogenolysis of $\left[\mathrm{Ni}\left(\mathrm{GaCp}^{*}\right)\left(\mathrm{PMe}_{3}\right)_{3}\right]$}

A series of complexes $\left[\mathrm{Ni}\left(\mathrm{GaCp}^{*}\right)_{x}\left(\mathrm{PMe}_{3}\right)_{4-x}\right](x=1,2)$ can be synthesized from $\left[\mathrm{Ni}(\mathrm{COD})_{2}\right], \mathrm{GaCp}^{*}$ and $\mathrm{PMe}_{3}$ in the appropriate stoichiometric ratios. ${ }^{40,41}$ The $\mathrm{Ni}_{1} \mathrm{Ga}_{1}$ complex $\left[\mathrm{Ni}\left(\mathrm{GaCp}^{*}\right)\left(\mathrm{PMe}_{3}\right)_{3}\right]$ was chosen as a representative example in order to probe the validity of the single-source precursor (SSP) decomposition concept to accomplish the selective formation of the corresponding $\mathrm{Ni}_{x} \mathrm{Ga}_{y}$ phases (Scheme 2) and to compare this concept with the dual-source pathway (vide supra).

A yellow solution of $\left[\mathrm{Ni}\left(\mathrm{GaCp}^{*}\right)\left(\mathrm{PMe}_{3}\right)_{3}\right]$ in $n$-decane was set under 4 bar $\mathrm{H}_{2}$ pressure and heated to $185^{\circ} \mathrm{C}$ for $60 \mathrm{~h}$ (Scheme 2; analytical data in the ESI†). The color of the solution gradually turns dark brown and the formation of a dark precipitate (NP4) is observed. The PXRD of NP4 is in accordance with the pattern reported for the $\mathrm{Ni}_{2} \mathrm{Ga}_{3}$ phase and that observed for NP2 (Fig. S10 in the ESI $\dagger$ ). After annealing of the sample $(20 \mathrm{~h}$ at $300{ }^{\circ} \mathrm{C}$ under a dynamic vacuum of $10^{-3}$ mbar) the reflections become sharper, but no phase transformation is observed.

The bright-field TEM images for NP4 (Fig. S8 in the ESI $\dagger$ ) show smaller particles $(5-20 \mathrm{~nm})$ as well as huge agglomerates

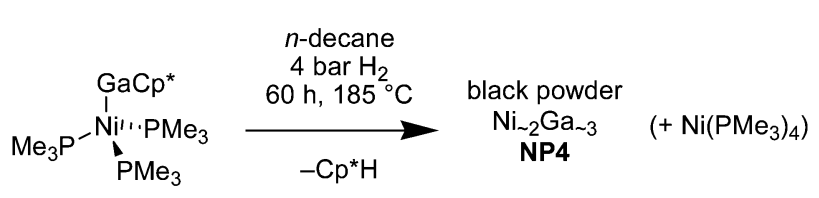

Scheme 2 Hydrogenolysis of the single-source precursor [Ni(GaCp*)(PMe $)_{3}$ ] in $n$-decane. 
(up to several $\mu \mathrm{m}$ ). The EDX data reveal substantial compositional variations with $\mathrm{Ni}$ : $\mathrm{Ga}$ ratios ranging between $1: 1$ to $1: 2( \pm 10 \%$ rel. error) and point to the presence of amorphous impurities (Fig. S9†). The data were taken from larger areas of the sample, i.e. multiple particles. The AAS data agree with an overall ratio of $2: 3$ (i.e. $\mathrm{Ni}_{2} \mathrm{Ga}_{2.93}$ ) which matches with the expectation from the PXRD pattern (vide supra). The only crystalline phase present was identified as $\mathrm{Ni}_{2} \mathrm{Ga}_{3}$ (Fig. S10 in the ESI $\dagger$ ) which proves that the impurities are amorphous. Interestingly, the observed $\mathrm{Ni}$ : Ga ratio is poor in nickel with respect to the precisely defined $1: 1$ stoichiometry of the single-source precursor starting material. The missing nickel forms $\left[\mathrm{Ni}\left(\mathrm{PR}_{3}\right)_{4}\right]$ as it was proven by a ${ }^{31} \mathrm{P}\left\{{ }^{1} \mathrm{H}\right\}$-NMR spectrum of the supernatant solution after the decomposition reaction. The spectrum shows one intense singlet peak at $-21.78 \mathrm{ppm}$, which neither corresponds to free $\mathrm{PMe}_{3}(-63.3 \mathrm{ppm})$ nor to the starting material $(-5.6 \mathrm{ppm}) .^{40}$ In fact, the observed chemical shift is very close to the one reported for the homoleptic $\mathrm{PMe}_{3}$ complex of nickel, namely $\left[\mathrm{Ni}\left(\mathrm{PR}_{3}\right)_{4}\right](-22.2 \mathrm{ppm}) .{ }^{41}$ This latter complex is surprisingly stable to hydrogenolysis under the applied conditions. It is noteworthy that the same effect occurs if a SSP with a sterically more demanding phosphine, i.e., $\left[\mathrm{Ni}\left(\mathrm{GaCp}^{*}\right)_{3}\left(\mathrm{PCy}_{3}\right)\right]$ is used (see Scheme S1, Fig. S11 and S12 in the ESI $\uparrow$ for further information). Thus Ni/Ga SSPs should not contain phosphine ligands. However, a selective synthesis of suitable SSPs of the general formula $\left[\mathrm{Ni}_{a}\left(\mathrm{GaCp}^{*}\right)_{b} \mathrm{~L}_{c}\right]$ with $a / b=1,2 / 3$ or 3 and $\mathrm{L}$ being a more innocent ligand, which does not form stable nickel complexes as side products during hydrogenolysis, is still to be accomplished.

\section{Colloidal $\mathrm{Ni} / \mathrm{Ga}$ nanoalloy particles in mesitylene or $\boldsymbol{n}$ - decane}

Based on the results of the above discussed co-hydrogenolysis of $\left[\mathrm{Ni}(\mathrm{COD})_{2}\right]$ and GaCp* which led to nanocrystalline powder samples of rather controlled $\mathrm{Ni} / \mathrm{Ga}$ phase compositions the same dual source precursor chemistry was employed to obtain colloidal solutions of the respective Ni/Ga nanoalloy particles. However, the organic reaction medium mesitylene or $n$-decane, respectively, did not prevent particle agglomeration. Therefore hexadecylamine (HDA) was chosen as an additive (surfactant). HDA is well known for reversible surface capping of metal and metal alloy nanoparticles and leads to the formation of rather stable colloidal solutions of non-agglomerated HDA-stabilized nanoparticles as it did here for the respective $\mathrm{Ni} / \mathrm{Ga}$ nanoalloys. Notably, co-hydrogenolysis using dodecanethiol or polyphenylene oxide (PPO), i.e., poly(oxy-2,6-dimethyl-1,4-phenylene), instead of HDA did not yield colloids, but black amorphous precipitates, which were not analyzed further. The as-synthesized HDA-stabilized particles were precipitated by addition of acetonitrile and were purified by washing with acetonitrile. The obtained samples NP5-7 were characterized by the same techniques as NP1-NP4. BF-TEM images of NP5-7 (Fig. 2) show individual particles of $5.0 \mathrm{~nm}( \pm 1.3 \mathrm{~nm}$ standard deviation).

EDX measurements of NP5-7 (Fig. S13a, S14 and S15a in the $\mathrm{ESI} \dagger$ ) indicate the formation of Ga-deficient materials with respect to the molar ratio of the precursors and the desired stoichiometry of the intermetallic phase. Thus, NP5 (targeting NiGa) shows a Ni : Ga ratio between $1: 0.54$ and $1: 0.73$, NP6 (targeting $\mathrm{Ni}_{2} \mathrm{Ga}_{3}$ ) shows a $\mathrm{Ni}: \mathrm{Ga}$ ratio between $2: 2.44$ and $2: 2.83$ and $\mathrm{NP7}$ (targeting $\mathrm{Ni}_{3} \mathrm{Ga}$ ) shows a $\mathrm{Ni}: \mathrm{Ga}$ ratio between $3: 0.52$ and $3: 0.61$ (Table S2a $\dagger$ ). X-ray photoelectron spectroscopy (XPS) analysis of three different regions of two samples of NP5 (targeting NiGa) gave Ni : Ga ratios between $1: 0.68$ and $1: 0.91$ and of NP7 (targeting $\mathrm{Ni}_{3} \mathrm{Ga}$ ) gave $\mathrm{Ni}: \mathrm{Ga}$ ratios between $3: 0.39$ and $3: 0.78$ (Fig. S13b, S15b and Table S2b in the ESI $\dagger$ ). Hydrogenation of the single-source precursor $\left[\mathrm{Ni}\left(\mathrm{GaCp}^{*}\right)\left(\mathrm{PMe}_{3}\right)_{3}\right]$ in $n$-decane in the presence of HDA as a stabilizer results in colloidal NiGa particles NP8. According to EDX (Fig. S16 and Table S2a in the ESI $\dagger$ ), the particles exhibit various compositions ranging from $1: 0.2$ to $1: 1.77$ and, hence, are not phase pure. A BF-TEM image (Fig. 2) shows particle sizes of $13 \mathrm{~nm}$ ( $\pm 5 \mathrm{~nm}$ standard deviation).

Probably excess HDA reduces the amount of gallium in the resulting intermetallic $\mathrm{Ni} / \mathrm{Ga}$ particles. It might form stable, soluble $\mathrm{Ga}$ (III) amino/amido/imido complexes or clusters by protolytic cleavage of $\mathrm{Cp} * \mathrm{H}$. At present, an analysis of the supernatant solutions after precipitation of the particles NP5-7 by mass spectrometry and ${ }^{1} \mathrm{H}$-NMR spectroscopy did not yield conclusive results. We did not study the phenomenon in great detail, because of the presented results in the next section.

According to BF-TEM images and EDX or XPS spectra all Ni/ Ga materials synthesized in conventional solvents were either
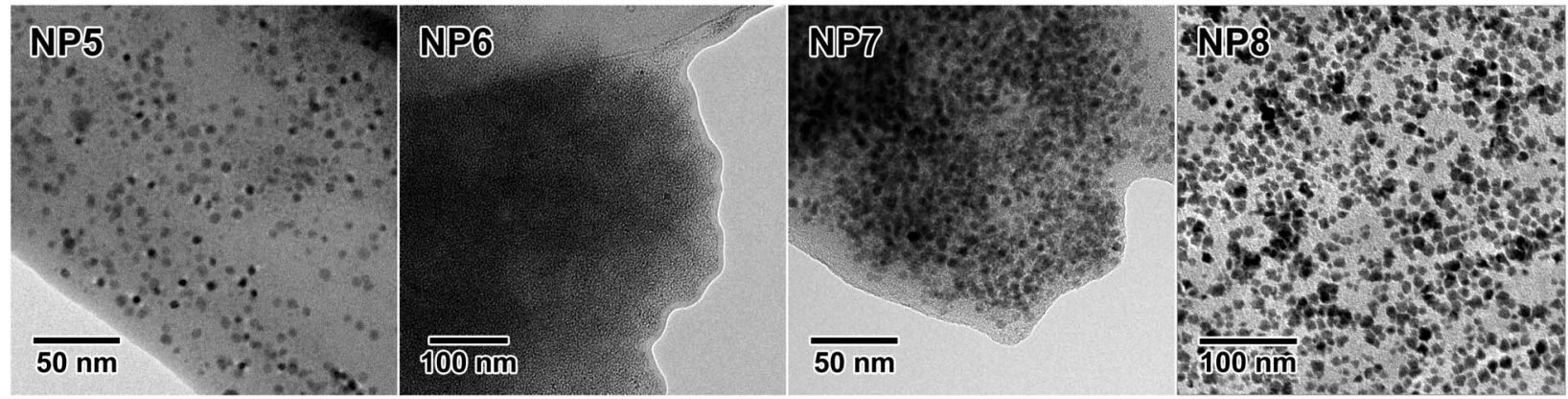

Fig. 2 BF-TEM images of HDA-stabilized colloidal mixed-phase Ni/Ga nanoalloys NP5-7 obtained by co-hydrogenolysis of [Ni(COD) 2 ] and $\mathrm{GaCp} *$ in mesitylene and of NP8 from hydrogenation of $\left[\mathrm{Ni}(\mathrm{GaCp} *)\left(\mathrm{PMe}_{3}\right)_{3}\right]$ in $n$-decane. 
heavily agglomerated or not phase pure. Thus, we refrained from further measurements.

\section{Free-standing $\mathrm{NiGa}$ and $\mathrm{Ni}_{3} \mathrm{Ga}$ nanoalloy particles obtained from $\left[\mathrm{Ni}(\mathrm{COD})_{2}\right]$ and $\mathrm{GaCp}^{*}$ in the ionic liquid $[\mathrm{BMIm}]\left[\mathrm{BF}_{4}\right]$}

Ionic liquids (ILs) are unique alternatives to conventional aqueous or organic solvents ${ }^{42}$ and have been introduced to materials chemistry in particular over the last few years. ${ }^{\mathbf{4 3 , 4 4}}$ Using ILs for the bottom-up wet-chemical preparation of advanced functional materials, including metal nanoparticles, has been shown to be very promising. ${ }^{45-49}$ The excellent solvation properties, high thermal stability, negligible vapor pressure, high ionic conductivity, and a broad liquid-state temperature range combined with the concomitant ionothermal synthesis method constitute particular advantages of ILs. ${ }^{50,51}$ Microwave (MW) induced thermal decomposition of organometallic compounds in ILs is a rapid and energy-saving means of access to metal nanoparticles because of the significant absorption efficiency of ILs of microwave energy due to their ionic character, high polarity, and high dielectric constant. ${ }^{52}$ In contrast to conductive heating, microwave radiation directly heats the reaction mixture and not primarily the vessel, i.e., it is the reaction mixture which absorbs the microwave energy. This leads to localized superheating, very fast and efficient heating rates. The temperature of $200{ }^{\circ} \mathrm{C}$ is reached within seconds. ${ }^{53-56}$ As soon as metal particles form from the thermally decomposed molecular precursors, they can absorb the MW radiation as well which leads to effective growth and annealing.

With these considerations in mind we investigated MW assisted co-pyrolysis of $\left[\mathrm{Ni}(\mathrm{COD})_{2}\right]$ and $\mathrm{GaCp}^{*}$ in $1: 1$ and $3: 1$

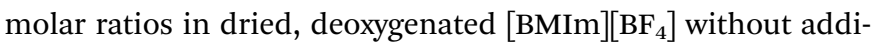
tional reduction by hydrogen. Quantitative decomposition of the precursors was achieved after only 10 minutes using a low power of $50 \mathrm{~W}$ at $220{ }^{\circ} \mathrm{C}$ in a nitrogen atmosphere (Scheme 3), which was verified by the complete absence of the characteristic $\left[\mathrm{Ni}(\mathrm{COD})_{2}\right]$ peaks and the presence of the expected peaks of free COD in the ${ }^{1} \mathrm{H}$ NMR spectrum (Fig. S17 in the ESI $\dagger$ ). Black colloidal solutions of $0.5 \mathrm{wt} \%$ of metal content were obtained. The respective samples are denoted as NP1-IL and NP3-IL. Highangle annular dark field scanning TEM (HAADF-STEM) yields characteristic diameters between 7 and $29 \mathrm{~nm}$ (average $14 \pm 5$ $\mathrm{nm}$ ) for NP1-IL and between 12 and $19 \mathrm{~nm}$ (average $17 \pm 4 \mathrm{~nm}$ ) for NP3-IL (Fig. 3 and 4).

$$
\begin{aligned}
& \text { [BMIm] }\left[\mathrm{BF}_{4}\right] \\
& \text { microwave irradiation } \\
& \begin{array}{l}
\text { NP1-IL: } a=1, b=1 \\
\text { NP3-IL: } a=3, b=1
\end{array}
\end{aligned}
$$

Scheme 3 Microwave (MW) induced thermal co-decomposition in the absence of $\mathrm{H}_{2}$ in different molar ratios using the ionic liquid (IL) $[B M I m]\left[B_{4}\right]$ as the reaction controlling and particle stabilizing medium.
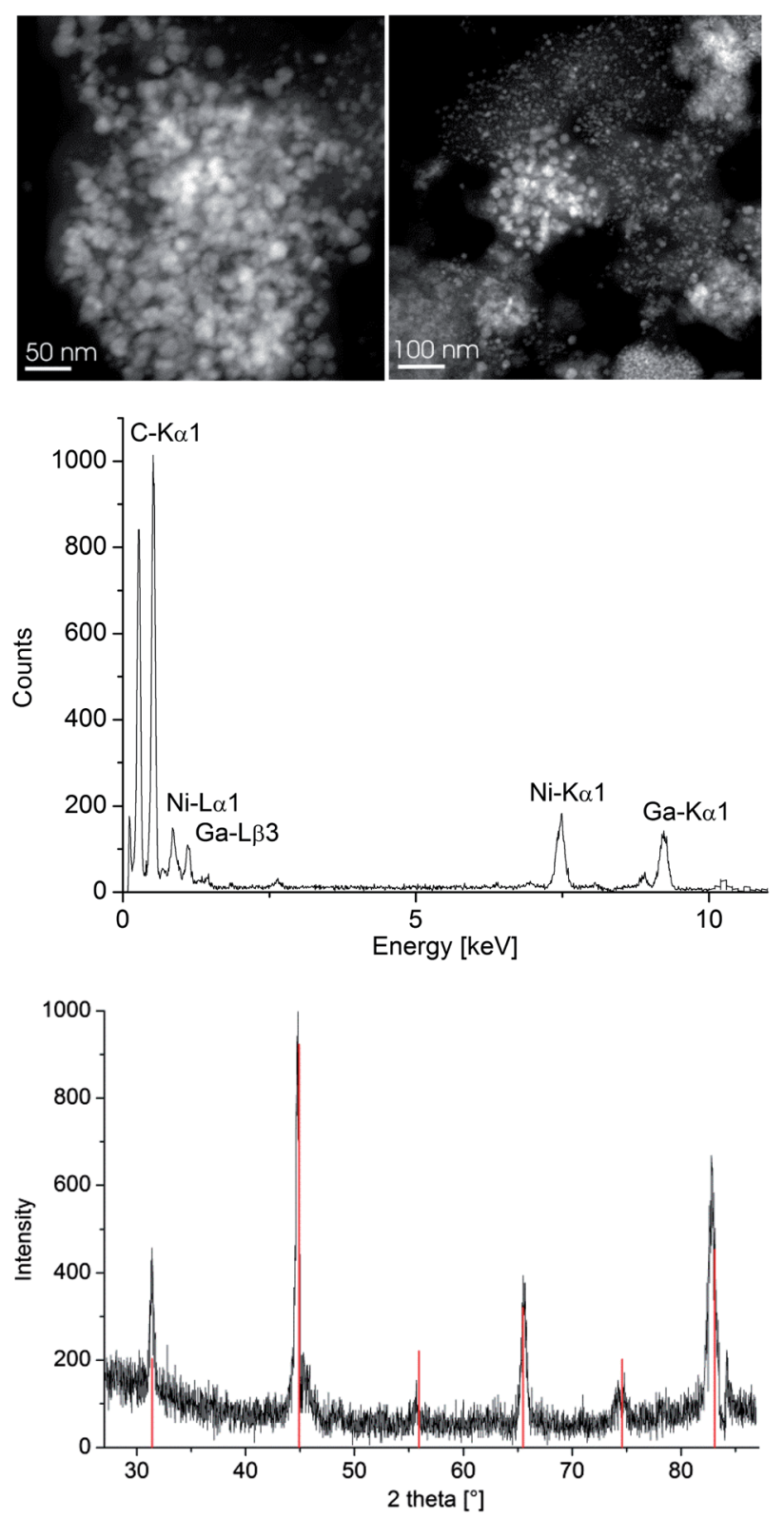

Fig. 3 HAADF-STEM image (top), EDX (middle), and PXRD (bottom) of NiGa nanoparticles NP1-IL in [BMIm] [BF 4 ]. Reference data in red taken from ICSD no. 103854 (NiGa). Averaged particle composition (at.\%) by EDX: $\mathrm{Ni} 49.2 \%$; $\mathrm{Ga} 50.8 \%(\mathrm{Ni}: \mathrm{Ga}=1: 1)$.

In comparison to the agglomerated, nanocrystalline powder samples NP1 and NP3 obtained by co-hydrogenolysis from mesitylene, co-pyrolysis in an IL resulted in non-agglomerated nanoparticles. The Ni/Ga-IL dispersions are stable. Even after two weeks the NPs did not agglomerate, as it was shown by HAADF-STEM measurements carried out after this time.

Nanoparticles of NP1-IL were precipitated from the IL solutions by addition of a sufficient amount of acetone and characterized by PXRD providing evidence for $\mathrm{NiGa}$ as the single crystalline component. The slightly broadened reflections suggest crystallite domain sizes of 21 ( $\pm 4 \mathrm{~nm}$ standard deviation) as calculated with the Scherrer equation. ${ }^{57}$ It is noteworthy that the peaks in the PXRD of NP1-IL (Fig. 3) do not exhibit a 

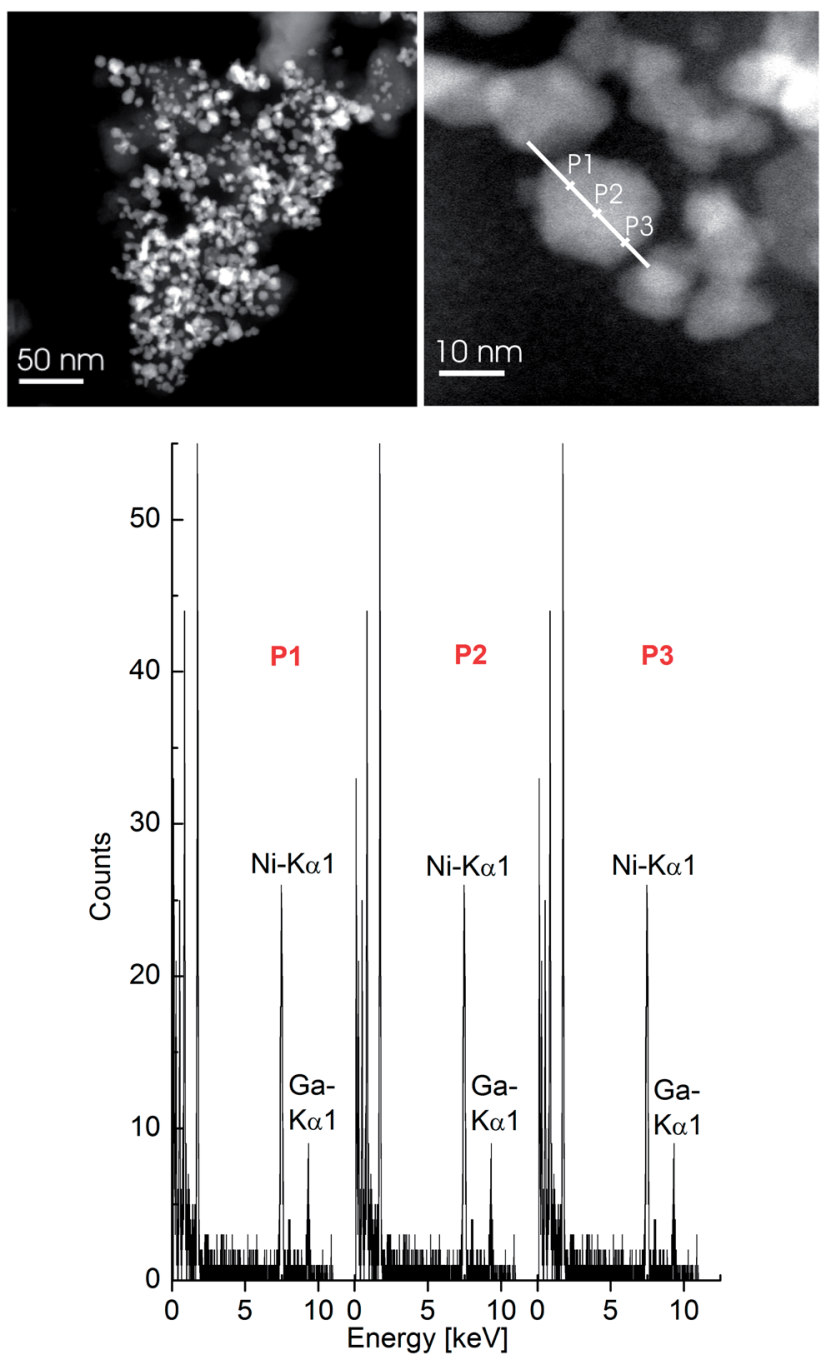

Fig. 4 HAADF-STEM images (top) and local EDX spectra (bottom) of NP3-IL recorded over an isolated particle along the white line (top right) with a $1 \mathrm{~nm}^{2}$ spatial resolution and an acquisition time of $30 \mathrm{~s}$. For additional points along the line see Fig. S18, $\uparrow$ for an overview see Fig. 5.

significant shift in $2 \theta$ in comparison with the NiGa reference peaks, which was the case in the PXRD of NP1 (Fig. 2). Interestingly, the pyrolysis and decomposition of both organometallic precursors occurred without hydrogenolysis by dihydrogen. This is somewhat surprising because of the quite robust nature of $\mathrm{GaCp}^{*}$. In conventional solvents $\mathrm{GaCp}^{*}$ is thermally stable up to $300{ }^{\circ} \mathrm{C}$ (in the absence of hydrogen). ${ }^{58}$ However, the reactivity of the imidazolium component of ILS with reactive metal centers has to be considered. It has been shown that in the course of metal nanoparticle formation from organometallic precursors in ILs, C-H/D activation/exchange processes may take place at molecular metal centers as well as at the surface of metal nanoparticles. Thus, nitrogen heterocyclic carbene species (NHCs) formed by decomposition of ILs may contribute to the stabilization of metal clusters and nanoparticles. ${ }^{59}$ Hence, cooperative mechanisms involving H-transfer from the transition metal (i.e. $\mathrm{Ni}$ ) to $\mathrm{Ga}$ and then the release of $\mathrm{Cp}^{*} \mathrm{H}$ need to be taken into account, even in the absence of additional hydrogen. ${ }^{60}$
The EDX spectra of NP3-IL for a single nanoparticle at different points as well as the average composition of 70-90 particles (Fig. 4 and 5) agree on a homogeneous phase of the composition $\mathrm{Ni}_{3} \mathrm{Ga}$. Fig. 4 illustrates EDX spectra at three (P1 to P3) out of six measured points (Fig. S18†) with $1 \mathrm{~nm}^{2}$ resolution across a single nanoparticle with Ni $71 \pm 5 \%$; Ga $29 \pm 5 \%$ $(\mathrm{Ni}: \mathrm{Ga} \approx 3: 1$ ) (larger instrumental errors due to a very small scan area).

Bimetallic nanoparticles can be differentiated into coreshell and alloy structures. ${ }^{\mathbf{6 1}}$ The formation of either structure depends on kinetic influences during metal reduction and nanoparticle growth processes as well as electron transfer processes between the metal species. For nano-alloy formation both metal precursor species must be reduced at the same rate and quantitatively. An inter-metal electron transfer of the type $\mathrm{M}(1)^{+}+\mathrm{M}(2) \rightarrow \mathrm{M}(1)+\mathrm{M}(2)^{+}$must be much slower to avoid metal segregation within a nano-cluster. The metal ratio of the formed alloy then corresponds to those of the precursors for quantitative reduction. The initial reduction according to $\mathrm{e}^{-}+$ $\mathrm{M}^{+} \rightarrow \mathrm{M}$ followed by metal aggregation $\mathrm{M}(1)+\mathrm{M}(2) \rightarrow\{\mathrm{M}(1)$ $\mathrm{M}(2)\}$ gives bimetallic nano-alloys. ${ }^{61}$

\section{Catalytic semihydrogenation of alkynes with NiGa}

The semihydrogenation of a $\mathrm{C} \equiv \mathrm{C}$ triple bond to a $\mathrm{C}=\mathrm{C}$ double bond is an important reaction in industrial and synthetic organic chemistry. Supported and modified noble (expensive) metal nanoparticles can be used in heterogeneous catalytic hydrogenation to prevent over-reduction to alkanes and to increase the stability of the catalyst. ${ }^{\mathbf{8 1 3 - 1 8}}$ Only a few reports were published on noble-metal-free heterogenous catalysts for alkyne semihydrogenation. These include nickel nanoparticles for the highly stereoselective cis semihydrogenation of internal alkynes ${ }^{62}$ and $\mathrm{Cu}_{3} \mathrm{Fe}$ and $\mathrm{Cu}_{2.75} \mathrm{Ni}_{0.25} \mathrm{Fe}$ for the gas-phase semihydrogenation of propyne to propene. ${ }^{9}$

We have tested Ni-NPs (from Ni(COD) $)_{2}$ ) and NiGa-NPs both in $[\mathrm{BMIm}]\left[\mathrm{BF}_{4}\right]$ under organic-solvent-free conditions for the (semi-)hydrogenation of 1-octyne (Scheme 4) and diphenylacetylene (Scheme 5).

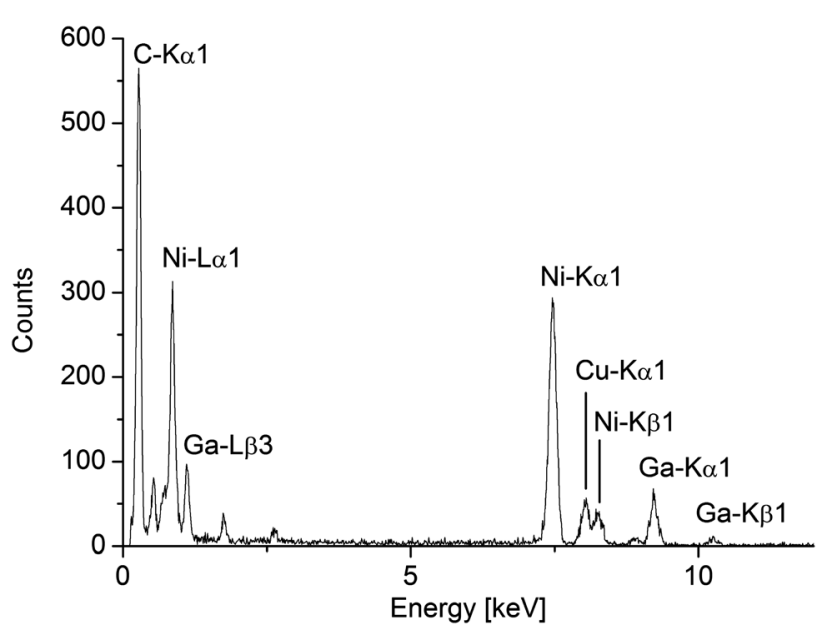

Fig. 5 EDX spectrum collected over 70-90 particles of NP3-IL. 
<smiles>C#CCCCCCC</smiles>

\begin{tabular}{|c|c|c|}
\hline \multirow[t]{3}{*}{$\begin{array}{l}\mathrm{H}_{2}, 120^{\circ} \mathrm{C}, \\
5 \text { bar, } 3 \mathrm{~h}\end{array}$} & $\begin{array}{r}\mathrm{Ni-NP} \\
\text { /[BMIm][B } \\
\text { Conversion: } 96 \%\end{array}$ & $\begin{array}{c}\text { NiGa-NP } \\
\text { /[BMIm] [BF } \\
\text { NP1-IL } \\
\text { 86-90\% }\end{array}$ \\
\hline & Selectivity: $3 \%$ & $90-94 \%$ \\
\hline & $97 \%$ & $6-10 \%$ \\
\hline
\end{tabular}

Scheme 4 Conversion rates and selectivity of the (semi-)hydrogenation of 1-octyne in the IL [BMIm] [BF 4 by Ni-NPs and NiGa NP1-IL. NP1-IL was tested thrice with new NiGa samples (cf. Table 1).

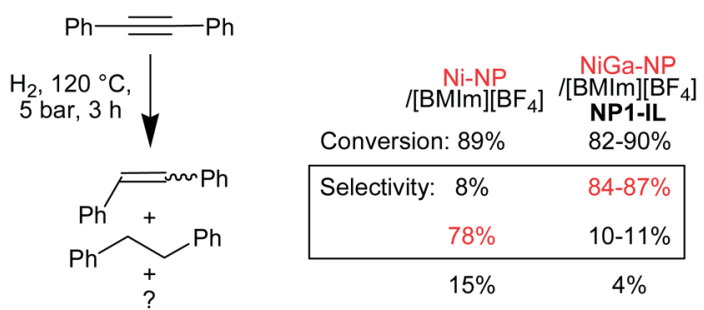

Scheme 5 Conversion rates and selectivity of the (semi-)hydrogenation of diphenylacetylene (tolan) in the $\mathrm{IL}[\mathrm{BMIm}]\left[\mathrm{BF}_{4}\right]$ by Ni-NPS and NiGa NP1-IL. NP1-IL was tested twice. Diphenylethylene is a cistrans-mixture.

Ni-NPs (median diameter $18 \pm 6 \mathrm{~nm}$, see Scheme S1, Fig. S19, S20 and Table S3 in the ESI $\dagger$ ) showed high conversion rates for the total hydrogenation of the triple bond and selectivity to octane $(97 \%)$ or diphenylethane $(78 \%)$. On the other hand NiGa-NPs from NP1-IL yielded primarily 1-octene or diphenylethylene with $94 \%$ or up to $87 \%$ selectivity, respectively.

The NiGa catalyst can easily be recovered after product removal and re-used again with fresh substrate. The semihydrogenation of 1-octyne could be run four times with the same catalyst charge and little loss of conversion or selectivity (Table 1).

After catalysis the NiGa nanoalloy particles have increased in size to $68( \pm 10) \mathrm{nm}$ but are still separate nanoparticles (Fig. 6).

Table 1 Semihydrogenation of 1-octyne with NiGa-NPs ${ }^{a}$

\begin{tabular}{lllll}
\hline & & & \multicolumn{2}{l}{ Selectivity (\%) } \\
\cline { 5 - 5 } Sample & Conversion (\%) & $\mathrm{TOF}^{b}\left[\mathrm{~h}^{-1}\right]$ & 1-Octene & Octane \\
\hline 1 & 89 & 138 & 93 & 7 \\
2 & 87 & 135 & 94 & 6 \\
$3 \mathrm{a}$ & 89 & 138 & 92 & 8 \\
$3 \mathrm{~b}$ & 90 & 139 & 91 & 9 \\
$3 \mathrm{c}$ & 88 & 136 & 90 & 10 \\
$3 \mathrm{~d}$ & 86 & 133 & 90 & 10
\end{tabular}

${ }^{a}$ In a typical catalytic test reaction $\left.0.1 \mathrm{~g} \mathrm{NiGa/[BMIm]}\right]\left[\mathrm{BF}_{4}\right]$ dispersion $(0.5 \mathrm{wt} \%=0.005 \mathrm{~g}$ in total metal, $39 \mu \mathrm{mol} \mathrm{NiGa})$ and $2 \mathrm{~g}(2.5 \mathrm{~mL}$, $18.1 \mathrm{mmol}$ ) of degassed dry 1-octyne (molar NiGa : substrate ratio = $1: 464$ ) were stirred under 5 bar $\mathrm{H}_{2}$ at $120{ }^{\circ} \mathrm{C}$ for $3 \mathrm{~h}$. Runs $3 \mathrm{a}-3 \mathrm{~d}$ were carried out with the same catalyst by removing the products in high vacuum at $50{ }^{\circ} \mathrm{C} .{ }^{b} \mathrm{TOF}=\mathrm{mol}$ product $/(\mathrm{mol}(\mathrm{NiGa}$, total metal $) \times$ time(h)).
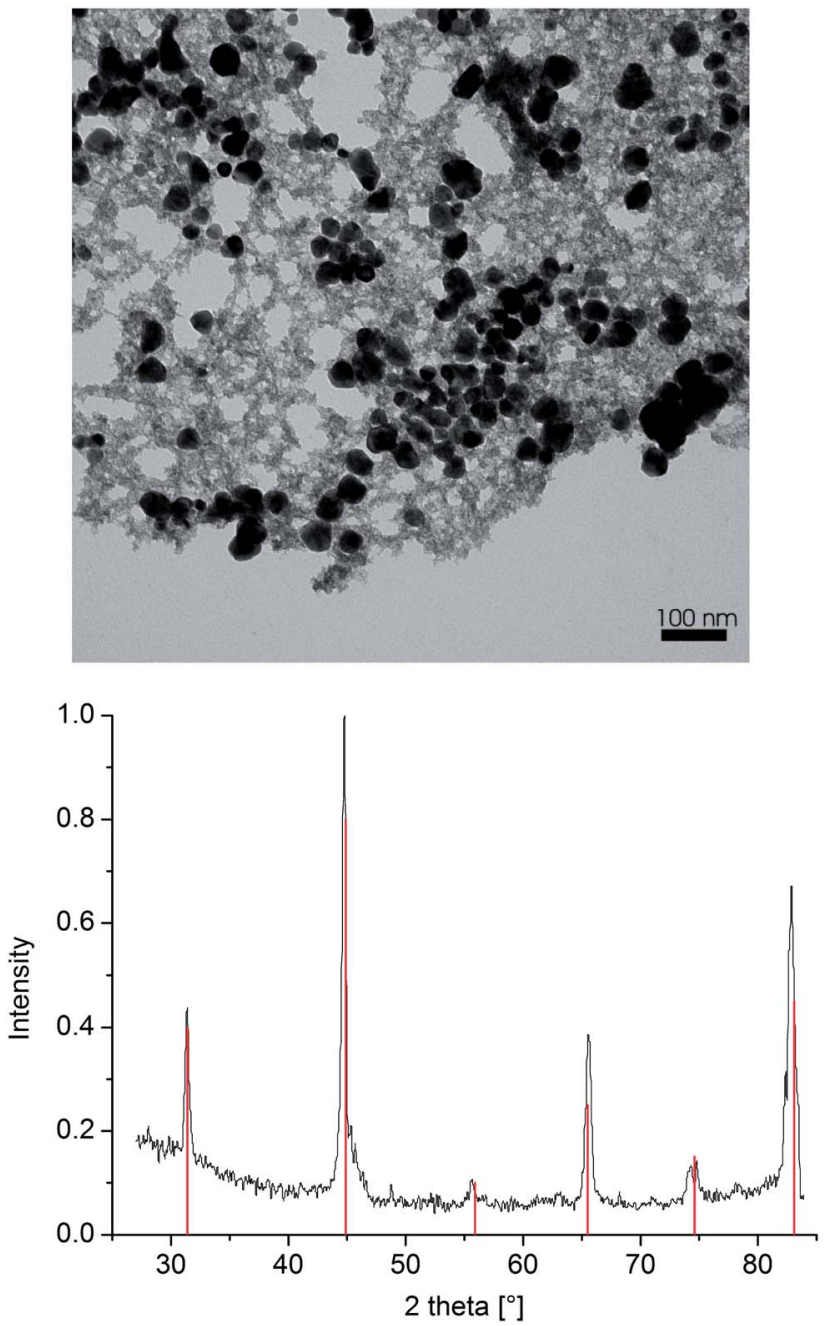

Fig. 6 TEM image (top) and PXRD (bottom) of NiGa-NPs after a $4^{\text {th }}$ run with catalyst recycling $(3 d$, Table 1$)$ in the catalytic 1-octyne hydrogenation. PXRD reference data in red taken from ICSD no. 103854 (NiGa) (cf. Fig. 3 bottom).

PXRD confirms the unchanged presence of a crystalline NiGa phase in $[\mathrm{BMIm}]\left[\mathrm{BF}_{4}\right]$ after catalysis (Fig. 6).

\section{Conclusions}

We have investigated the soft wet-chemical preparation of nanocrystalline $\mathrm{Ni} / \mathrm{Ga}$ alloy materials $\mathrm{NiGa}, \mathrm{Ni}_{2} \mathrm{Ga}_{3}$, and $\mathrm{Ni}_{3} \mathrm{Ga}$ in non-aqueous media. The dual source precursor concept based on the organometallic precursors $\left[\mathrm{Ni}(\mathrm{COD})_{2}\right]$ and $\mathrm{GaCp}$ * proved to be successful, while single-source precursors such as $\left[\mathrm{Ni}\left(\mathrm{GaCp}^{*}\right)\left(\mathrm{PMe}_{3}\right)_{3}\right]$ did not yield the expected $\mathrm{Ni} / \mathrm{Ga}$ phase due to the formation of stable $\left[\mathrm{Ni}\left(\mathrm{PMe}_{3}\right)_{4}\right]$ as a side product. Cohydrogenolysis in the conventional organic solvent mesitylene turned out to be less reliable and selective in terms of yielding specific $\mathrm{Ni}_{x} \mathrm{Ga}_{y}$ phases than the co-pyrolysis conducted in the ionic liquid (IL) under microwave heating and in the absence of hydrogen. In particular, the reaction control and intrinsic particle stabilizing properties of ILs turned out to be advantageous, if non-agglomerated nanoalloy particles of 
homogeneous composition and high crystallinity are the desired products. Very stable colloids of nanocrystalline NiGa and $\mathrm{Ni}_{3} \mathrm{Ga}$ particles in the ionic liquid $[\mathrm{BMIm}]\left[\mathrm{BF}_{4}\right]$ were obtained. In contrast, in the case of co-hydrogenolytic preparation of the respective $\mathrm{Ni} / \mathrm{Ga}$ colloids in conventional organic media, hexadecylamine (HDA) was needed as a surfactant additive. HDA turned out to be incompatible with the chemistry of GaCp* and caused undesired loss of the gallium component. Thus, the advantage of the ionic liquid as the reaction medium for nanoalloy synthesis is based on three aspects: (i) the nonnecessity of $\mathrm{H}_{2}$ and (ii) no additional surfactant is needed and (iii) the shorter reaction time (10 min versus several hours) with less energy consumed ( $50 \mathrm{~W}$ microwave energy focused on the sample versus several hundred Watts to heat an oil bath with a sample tube to $150{ }^{\circ} \mathrm{C}$ ). From the precursor chemistry point of view the most attractive aspect might be the possible involvement of imidazolium $\mathrm{CH}$ activation and the formation of nitrogen heterocyclic carbene species in the course of the decomposition mechanism of the organogroup-13 precursor GaCp*. This aspect needs further investigations.

The synthesis of intermetallic $\mathrm{Ni}_{x} \mathrm{Ga}_{y}$ nanoparticles is a proof-of-concept for the easy and straightforward formation of nanoalloys from organometallic precursors in ILs. The catalytic NiGa semihydrogenation properties are further evidence that intermetallic Hume-Rothery phases of a metal from $\mathrm{Cr}-\mathrm{Ni}$ and a metal from groups 12-15 can mimic and replace costly noble metal catalysts. Hume-Rothery type nanoalloys of $\mathrm{Co} / \mathrm{Al}, \mathrm{Ni} / \mathrm{Al}$ and $\mathrm{Cu} / \mathrm{Al}$ were already obtained by one of us by co-hydrogenolysis of the corresponding transition metal precursors. ${ }^{22}$ The goal would be to obtain $\mathrm{Fe} / \mathrm{Al}$ nanoalloys either from separate $\mathrm{Fe}$ and $\mathrm{Al}$ precursors or from $\mathrm{Fe}-\mathrm{Al}$ mixed-metal clusters, such as $\left[\mathrm{Fe}(\mathrm{AlCp} *)_{5}\right]{ }^{63}$

\section{Experimental section}

All experimental manipulations were performed under a purified inert nitrogen or argon atmosphere by using standard Schlenk line and glove-box techniques. Syntheses of NP1-NP8 were carried out in $100 \mathrm{~mL}$ Fischer-Porter vessels. Syntheses of NP1-IL and NP3-IL were done in septum-sealed $10 \mathrm{~mL}$ CEM microwave-vessels in a CEM Discover microwave.

The solvents (acetone, acetonitrile, $n$-hexane, toluene, tetrahydrofuran) were dried using the MBraun solvent purification system. Mesitylene and $n$-decane were dried by passing the solvent over activated $\mathrm{Al}_{2} \mathrm{O}_{3}$ (neutral) column. The final $\mathrm{H}_{2} \mathrm{O}$ content was controlled by Karl Fischer titration. The metal precursors $\mathrm{Ni}(\mathrm{COD})_{2},{ }^{64} \mathrm{GaCp} *,{ }^{65}$ and $\left[\mathrm{Ni}\left(\mathrm{GaCp}^{*}\right)\left(\mathrm{PMe}_{3}\right)_{3}\right]^{38}$ were prepared according to the previously reported procedures under strictly inert dry argon conditions. Poly(2,6-dimethyl-1,4-phenylene oxide) (PPO), hexadecylamine (HDA) and dodecanethiol were purchased from Acros Organics. HDA was dried and degassed prior to use.

The ionic liquid $[\mathrm{BMIm}]\left[\mathrm{BF}_{4}\right]$ was synthesized by reacting 1methylimidazole with 1-chlorobutane to yield first [BMIm] [Cl] which was further reacted with $\mathrm{HBF}_{4}$ to give [BMIm] $\left[\mathrm{BF}_{4}\right]$. The IL was dried under high vacuum $\left(10^{-7} \mathrm{mbar}\right)$ at $80{ }^{\circ} \mathrm{C}$ for several days. Quantitative anion exchange and, thus, IL purity of $>99 \%$ was assessed by ion chromatography (Dionex ICS-1100, with IonPac ${ }^{\circledR}$ AS14, $4 \times 250 \mathrm{~mm}$ column). Water content measured by coulometric Karl Fischer titration (ECH/ANALYTIK JENA AQUA 40.00) was below 10 ppm.

\section{Analytical techniques and instrumentation}

Metal analysis was conducted at the laboratory of microanalysis of the Ruhr University Bochum (CHNSO: Vario EL by Elementar Hanau). AAS analysis for the metal content of Ga and Ni was undertaken using a Vario 6 AAS instrument from Analytik Jena. The samples were dissolved in aqua regia or $\mathrm{HCl}$ and $\mathrm{H}_{2} \mathrm{SO}_{4}$. NMR spectra were recorded on a Bruker Avance DPX-250 spectrometer $\left({ }^{1} \mathrm{H}, 250 \mathrm{MHz} ;{ }^{13} \mathrm{C}, 62.9 \mathrm{MHZ} ;{ }^{31} \mathrm{P}, 101.3 \mathrm{MHz}\right)$ at $298 \mathrm{~K}$ in $\mathrm{C}_{6} \mathrm{D}_{6}$ and toluene- $\mathrm{d}_{8}$ and the chemical shifts are referenced to the residual solvent peaks.

Powder X-ray diffraction (PXRD) data for the NP1-NP8 samples were measured on a D8-Advance-Bruker-AXS-diffractometer (Cu-K $\alpha$-radiation, $1.54178 \AA$, scan step $0.0141^{\circ} 2 \theta$, heating current $30 \mathrm{~mA}$ ) in Bragg-Brentano $\theta$-2 $\theta$-geometry, using a Göbel mirror as a monochromator and a position sensitive detector. The powder samples were prepared under argon using Lindeman capillaries (diameter $0.5,0.7$ or $1.0 \mathrm{~mm}$ ). The capillaries were flame-sealed prior to measurements. The detector was calibrated to the reflections of crystalline $\alpha-\mathrm{Al}_{2} \mathrm{O}_{3}$. Measurements were done to collect the $2 \theta$ range of $10-90^{\circ}$.

PXRD data for NP1-IL and NP3-IL samples were measured at ambient temperature on a Bruker D2 Phaser using a flat sample holder and $\mathrm{Cu}-\mathrm{K} \alpha$ radiation $(\lambda=1.54182 \AA)$. Samples had been precipitated with acetone from the NP/IL dispersion and washed with acetonitrile.

TEM samples of NP1-NP8 were prepared as diluted solutions or suspensions in toluene and deposited on carbon coated copper grids. Bright-field transmission electron microscopy (BF-TEM) images were acquired on a Philips CM30 equipped with a Schottky field emission gun (FEG) operating at $300 \mathrm{kV}$. BF-TEM together with energy-dispersive X-ray spectroscopy (EDX) were carried out using a Philips CM20 microscope equipped with $\mathrm{LaB}_{6}$ filament operating at $200 \mathrm{kV}$ acceleration voltage and a Hitachi $\mathrm{H}-8100$ microscope equipped with a $\mathrm{LaB}_{6}$ filament operating at $200 \mathrm{kV}$ acceleration voltage. BF-TEM, HR-TEM images, and EDX were acquired on a Tecnai FEI G2 microscope equipped with a FEG operating at $200 \mathrm{kV}$.

HAADF-STEM images of NP-IL samples were taken at room temperature using a Tecnai FEI G20 TEM equipped with a FEG operating at an accelerating voltage of $200 \mathrm{kV}$. Samples were deposited on $200 \mu \mathrm{m}$ carbon-coated gold grids. The size distribution was calculated from a manual diameter determination over a minimum of 50 isolated particles.

All EDX spectra acquired in STEM mode were averaged scans over selected areas of $\sim 100 \times 100 \mathrm{~nm}^{2}$. The EDX spectra of an isolated particle from NP3-IL were measured at several points with a spatial resolution of $1 \mathrm{~nm}^{2}$ (acquisition time of $30 \mathrm{~s}$ at each point). Thereby the instrumental errors of this high-resolution EDX scan led to an estimated standard deviation of \pm 10 $15 \%$ rel. error. 
The X-ray photoelectron spectroscopy, XPS-(ESCA), measurement was performed with a Fisons/VG Scientific ESCALAB 200X XP-spectrometer, operating at room temperature, at a pressure of $1.0 \times 10^{-8}$ bar and a sample angle of $30^{\circ}$. Using this spectrometer, electron spectra were recorded using polychromatic $\mathrm{Al}-\mathrm{K} \alpha$ excitation $(14 \mathrm{kV}, 20 \mathrm{~mA})$ and an emission angle of $0^{\circ}$. Calibration of the XPS was carried out by recording spectra, using Al- $\mathrm{K}_{\text {alpha }} \mathrm{X}$-rays, from clean samples of copper, silver and gold, at $20 \mathrm{eV}$ and $10 \mathrm{eV}$ pass energies and comparison with reference values.

GC/MS data were recorded on a Thermo Finnigan Trace DSQ.

\section{Preparation of sample NP1 (NiGa)}

In a Fischer-Porter vessel, $0.400 \mathrm{~g}$ of $\left[\mathrm{Ni}(\mathrm{COD})_{2}\right](1.454 \mathrm{mmol})$ and $0.296 \mathrm{~g}$ of GaCp* $(1.450 \mathrm{mmol})$ were dissolved in mesitylene (15 mL). The resultant yellow-orange solution was degassed for 5 min and set to 4 bar $\mathrm{H}_{2}$ pressure. The bottle was then placed into an oil bath at $150{ }^{\circ} \mathrm{C}$. After $10 \mathrm{~min}$ of heating the solution became dark red, and slowly changed to dark brown after 20 min with the formation of a black precipitate. The mixture was stirred for $3 \mathrm{~h}$ at the same temperature, where upon the solution became colorless with a black precipitate. After cooling to room temperature $\left(25{ }^{\circ} \mathrm{C}\right)$, the colorless supernatant was decanted under argon and the black material was washed several times with toluene $(3 \times 10 \mathrm{~mL})$, followed by $n$-hexane $(3 \times 10 \mathrm{~mL})$. The resultant material was dried under vacuum overnight at $50{ }^{\circ} \mathrm{C}$. Yield: 0.184 g. AAS: Ni $39.69 \mathrm{wt} \%$ and $\mathrm{Ga} 50.27 \mathrm{wt} \%$; $n(\mathrm{Ni}): n(\mathrm{Ga})=0.93 . \mathrm{XRD}$ reflections $\left(2 \theta /^{\circ}\right): 31.38,44.85,55.64$, $64.45,74.36$ and 82.66 . EDX analysis ( $\pm 4 \%$ relative error): Ni 38 at.\%; $\mathrm{Ga} 38$ at.\%; $\mathrm{Ni}: \mathrm{Ga}=1.0$.

\section{Preparation of sample NP2 $\left(\mathrm{Ni}_{2} \mathrm{Ga}_{3}\right)$}

In a Fischer-Porter vessel, $0.600 \mathrm{~g}$ of $\left[\mathrm{Ni}(\mathrm{COD})_{2}\right](2.181 \mathrm{mmol})$ and $0.667 \mathrm{~g}$ of GaCp* (3.272 mmol) were dissolved in mesitylene $(30 \mathrm{~mL})$. The resultant yellow-orange solution was degassed for 3 min and set to 4 bar $\mathrm{H}_{2}$ pressure. The bottle was then placed into an oil bath at $150{ }^{\circ} \mathrm{C}$. The resultant clear red reaction mixture became dark red, then brown over a period of $15 \mathrm{~min}$. After $30 \mathrm{~min}$, formation of a black precipitate was observed. During the reaction a large drop in the hydrogen pressure had taken place. The reaction mixture was heated for $24 \mathrm{~h}$, and cooled to room temperature. The resultant suspension was filtered to separate the black precipitate. This was then washed several times with toluene $(4 \times 20 \mathrm{~mL})$, followed by $n$-hexane $(3 \times 20 \mathrm{~mL})$ and dried under vacuum overnight. Yield: $0.273 \mathrm{~g}$. AAS: Ni $32.54 \mathrm{wt} \%$ and $\mathrm{Ga} 59.52 \mathrm{wt} \% ; n(\mathrm{Ni}): n(\mathrm{Ga})=0.65 ; \mathrm{XRD}$ reflections $\left(2 \theta /^{\circ}\right)$ : 18.19 ( $\left.\begin{array}{lll}0 & 0 & 1\end{array}\right), 25.39$ (1 $\left.\begin{array}{lll}1 & 0\end{array}\right), 31.30$ (1 $\left.\begin{array}{lll}1 & 0 & 1\end{array}\right), 36.82$

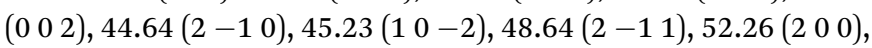

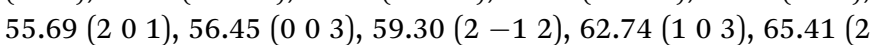
$02), 71.13(3-10), 73.99(3-11)$ and $74.75(2-13)$. Calculated particle size according to the Scherrer equation: ${ }^{55} 3-6 \mathrm{~nm}$.

\section{Preparation of sample NP3 $\left(\mathrm{Ni}_{3} \mathrm{Ga}\right)$}

Samples of $0.404 \mathrm{~g}$ of $\left[\mathrm{Ni}(\mathrm{COD})_{2}\right](1.469 \mathrm{mmol})$ and $0.100 \mathrm{~g}$ of GaCp* (0.489 mmol) were combined in a Fischer-Porter vessel in mesitylene $(20 \mathrm{~mL})$. The resultant yellow reaction mixture was degassed for $10 \mathrm{~min}$ at room temperature, set to 4 bar $\mathrm{H}_{2}$ pressure and the Fischer-Porter vessel placed in an oil bath at $150{ }^{\circ} \mathrm{C}$. After $5 \mathrm{~min}$, the color of the reaction mixture changed to dark-brown, then after 15 min formation of a black precipitate was observed. The mixture was stirred for $6 \mathrm{~h}$, where upon the solution became colorless. After cooling to room temperature the colorless supernatant was decanted under an argon atmosphere and the black material was washed several times with toluene $(6 \times 10 \mathrm{~mL})$, followed by $n$-hexane $(4 \times 10 \mathrm{~mL})$. Thereafter, the residual solvent and hydrocarbon byproducts were removed in vacuum and the black residue was thoroughly dried under vacuum overnight at $50{ }^{\circ} \mathrm{C}$. Yield: $0.130 \mathrm{~g}$. AAS: Ni 64.16 $\mathrm{wt} \%$ and $\mathrm{Ga} 27.28 \mathrm{wt} \% ; n(\mathrm{Ni}): n(\mathrm{Ga})=2.79$. XRD reflections $\left(2 \theta /^{\circ}\right): 43.68\left(\begin{array}{lll}1 & 1 & 1\end{array}\right), 50.52\left(\begin{array}{lll}2 & 0 & 0\end{array}\right)$ and 74.62 (2 20 ). EDX analysis ( $\pm 4 \%$ relative error): $\mathrm{Ni} 46.6$ at.\%, Ga 15.3 at.\%; $n(\mathrm{Ni}): n(\mathrm{Ga})=$ 3.04 .

\section{Hydrogenolysis of $\left[\mathrm{Ni}\left(\mathrm{GaCp}^{*}\right)\left(\mathrm{PMe}_{3}\right)_{3}\right]$ (sample NP4)}

In a Fischer-Porter vessel, $1.140 \mathrm{~g}$ of $\left[\mathrm{Ni}\left(\mathrm{GaCp}^{*}\right)\left(\mathrm{PMe}_{3}\right)_{3}\right]$ $(2.326 \mathrm{mmol})$ was dissolved in $n$-decane $(25 \mathrm{~mL})$, pressurized with 4 bar $\mathrm{H}_{2}$ and placed into an oil bath which was pre-heated to $185{ }^{\circ} \mathrm{C}$. After $30 \mathrm{~min}$ of stirring at this temperature the colour of the solution changed to dark brown with slow formation of a black/brown precipitate. This mixture was further heated for $60 \mathrm{~h}$. After cooling to room temperature, the suspension was transferred into a Schlenk tube and centrifuged to separate the black precipitate, which was then washed with $n$-hexane $(5 \times$ $20 \mathrm{~mL}$ ) till all the washings were colourless and dried in vacuum. Yield: $250 \mathrm{mg}$. AAS: Ni $33.76 \mathrm{wt} \%$ and Ga $58.75 \mathrm{wt} \%$. XRD reflections $\left(2 \theta /^{\circ}\right): 25.33$ (100), 31.27 (101), 45.11(102), 48.63 (111), 52.16 (200), 55.47 (201), 62.92 (103), 65.57 (202), 71.06 (210), 74.48 (113).

\section{Preparation of nickel-gallium colloidal nanoparticles (NP5)}

In a Fischer-Porter vessel, $0.200 \mathrm{~g}$ of [Ni(COD) $\left.)_{2}\right](0.727 \mathrm{mmol})$, $0.148 \mathrm{~g}$ of $\mathrm{GaCp}^{*}(0.725 \mathrm{mmol})$ and dry HDA (hexadecylamine) (0.098 g, $0.407 \mathrm{mmol}$ ) were dissolved in mesitylene $(7 \mathrm{~mL})$. The resultant yellow-orange solution was degassed for $5 \mathrm{~min}$ and set to 4 bar $\mathrm{H}_{2}$ pressure. The bottle was then placed into an oil bath at $150{ }^{\circ} \mathrm{C}$. After $10 \mathrm{~min}$ of heating the solution changed to dark brown/black. The mixture was stirred for $3 \mathrm{~h}$ at the same temperature. After cooling to room temperature $\left(25^{\circ} \mathrm{C}\right)$, the stabilized black particles were precipitated by dry acetonitrile and washed three times with dry acetonitrile $(7 \mathrm{~mL})$ by ultrasonic treatment and centrifugation. After this the black material was suspended in dry toluene $(10 \mathrm{~mL})$. Yield: $0.112 \mathrm{~g}$. EDX analysis $( \pm 0.26 \%$ relative error): $\mathrm{Ni}$ 61.93\%; $\mathrm{Ga} 38.06 \%$ ( $k$-factors: Ni 1.511, Ga 1.934).

\section{Preparation of nickel-gallium colloidal nanoparticles (NP6)}

In a Fischer-Porter vessel, $0.300 \mathrm{~g}$ of [Ni(COD) $)_{2}$ (1.091 mmol), $0.222 \mathrm{~g}$ of GaCp* (1.083 mmol) and dry HDA (hexadecylamine) (0.395 g, $1.637 \mathrm{mmol}$ ) were dissolved in mesitylene $(7 \mathrm{~mL})$. The resultant yellow-orange solution was degassed for $5 \mathrm{~min}$ and set to 4 bar $\mathrm{H}_{2}$ pressure. The bottle was then placed into an oil bath at $150{ }^{\circ} \mathrm{C}$. After $10 \mathrm{~min}$ of heating the solution changed to dark 
brown/black. The mixture was stirred for $24 \mathrm{~h}$ at the same temperature. After cooling to room temperature $\left(25^{\circ} \mathrm{C}\right)$, the stabilized black particles were precipitated by dry acetonitrile and washed three times with dry acetonitrile $(7 \mathrm{~mL})$ by ultrasonic treatment and centrifugation. The washing solution was decanted every time. After this the black material was suspended in dry toluene $(10 \mathrm{~mL})$. Yield: $0.184 \mathrm{~g}$. EDX analysis ( $\mathrm{Ni} \pm 0.41 \%$, Ga $\pm 0.64 \%$ relative error): $\mathrm{Ni} 37.36 \%$; Ga $62.36 \%$ ( $k$-factors: Ni 1.511, Ga 1.934).

\section{Preparation of nickel-gallium colloidal nanoparticles (NP7)}

In a Fischer-Porter vessel, $0.150 \mathrm{~g}$ of $\left[\mathrm{Ni}(\mathrm{COD})_{2}\right](0.545 \mathrm{mmol})$, $0.037 \mathrm{~g}$ of $\mathrm{GaCp} *(0.181 \mathrm{mmol})$ and dry HDA (hexadecylamine) $(0.197 \mathrm{~g}, 0.818 \mathrm{mmol})$ were dissolved in mesitylene $(7 \mathrm{~mL})$. The resultant yellow-orange solution was degassed for $5 \mathrm{~min}$ and set to 4 bar $\mathrm{H}_{2}$ pressure. The bottle was then placed into an oil bath at $150{ }^{\circ} \mathrm{C}$. After $10 \mathrm{~min}$ of heating the solution changed to dark brown/black. The mixture was stirred for $6 \mathrm{~h}$ at the same temperature. After cooling to room temperature $\left(25^{\circ} \mathrm{C}\right)$, the stabilized black particles were precipitated by addition of dry acetonitrile and washed three times with dry acetonitrile $(7 \mathrm{~mL})$ by ultrasonic treatment and centrifugation. The washing solution was decanted every time. After this the black material was suspended in dry toluene $(10 \mathrm{~mL})$. Yield: $0.074 \mathrm{~g}$. EDX analysis ( $\mathrm{Ni} \pm 0.36 \%, \mathrm{Ga} \pm 0.16 \%$ relative error): $\mathrm{Ni} 84.47 \%$; Ga $15.25 \%$ ( $k$-factors: Ni 1.511, Ga 1.934).

\section{Preparation of nickel-gallium colloidal nanoparticles (NP8)}

A Fischer-Porter vessel was charged with $0.500 \mathrm{~g}$ $\left[\mathrm{Ni}\left(\mathrm{GaCp}^{*}\right)\left(\mathrm{PMe}_{3}\right)_{3}\right](1.016 \mathrm{mmol})$ and $1.227 \mathrm{~g}$ dry HDA (hexadecylamine) $(5.052 \mathrm{mmol})$. To this reaction mixture $n$-decane $(20 \mathrm{~mL})$ was added. The resultant yellow reaction mixture was degassed for $15 \mathrm{~min}$ at, set to 4 bar $\mathrm{H}_{2}$ pressure and the FischerPorter vessel was placed in an oil bath at $185{ }^{\circ} \mathrm{C}$. After $10 \mathrm{~min}$ the mixture became brown, then dark brown without the formation of any precipitate. The mixture was then heated for $15 \mathrm{~h}$. The resultant reaction mixture was cooled to room temperature and the dark brown solution was transferred into a Schlenk tube. Dry ethanol $(100 \mathrm{~mL})$ was added and stirred for 2 h. The resulting cloudy solution was centrifuged to get a dark brown semi-solid. This was then washed with dry methanol, followed by ethanol $(2 \times 20 \mathrm{~mL})$ and dried under vacuum for 3 days. Yield: $32 \mathrm{mg}$. IR ( $\nu, \mathrm{cm}^{-1}$, neat): 3245 (vw), 3115 (vw), 2935 (vs), 2894 (vs), 2826 (vs), 1588 (w), 1454 (w), 1397 (w), 1249 (vs), 1080 (s), 1008 (vs), 860 (w), 791(vs), 713 (w), 681 (w). DLS (in dry toluene): $12-40 \mathrm{~nm}$ particle size. XRD reflections $\left(2 \theta /^{\circ}\right): 31.38$, $38.01,45.21,44.75,48.71,57.21,62.87,65.66$ and 70.26 .

\section{Preparation of sample NP1-IL (NiGa colloid in an ionic liquid)}

Co-decomposition of $\left[\mathrm{Ni}(\mathrm{COD})_{2}\right](13.3 \mathrm{mg}, 0.048 \mathrm{mmol})$ and GaCp* (9.9 mg, $0.048 \mathrm{mmol}$ ) by means of microwave irradiation was carried out under nitrogen. In a typical reaction, the precursor powders were dissolved/suspended under a nitrogen atmosphere at room temperature in dried and deoxygenated $[\mathrm{BMIm}]\left[\mathrm{BF}_{4}\right]\left(1 \mathrm{~mL}\right.$, density $\left.[\mathrm{BMIm}]\left[\mathrm{BF}_{4}\right]: 1.21 \mathrm{~g} \mathrm{~mL}^{-1}, 1.21 \mathrm{~g}\right)$ for a $0.5 \mathrm{wt} \% \mathrm{M}-\mathrm{NP} /[\mathrm{BMIm}]\left[\mathrm{BF}_{4}\right]$ dispersion. For the synthesis, the mixture was placed in a microwave (CEM, Discover) under an inert nitrogen atmosphere and the conversion was finished within $10 \mathrm{~min}$ at a power of $50 \mathrm{~W}$ and a temperature of $220^{\circ} \mathrm{C}$. Each decomposition reaction was carried out at least twice. XRD reflections $\left(2 \theta /^{\circ}\right): 31.4,44.9,55.9,65.5,74.6$ and 83.3. EDX analysis ( $\pm 1.7 \%$ relative error): $\mathrm{Ni} 49.0 \%$; Ga $51.0 \%$ ( $k$-factors: Ni: 1.511, Ga: 1.934).

\section{Preparation of NP3-IL ( $\mathrm{Ni}_{3} \mathrm{Ga}$ colloid in an ionic liquid)}

The co-decomposition of [Ni(COD $\left.)_{2}\right](13.5 \mathrm{mg}, 0.049 \mathrm{mmol})$ and GaCp* (3.3 mg, $0.016 \mathrm{mmol}$ ) was carried as before for NP1-IL. EDX analysis on a single particle with $\sim 14 \mathrm{~nm}$ diameter (cf. Fig. 4) (at.\%) ( $k$-factors: Ni: 1.511, Ga: 1.934): P1: Ni 71\%; Ga $29 \%$ ( $\pm 10-15 \%$ relative error), P2: Ni 71\%; Ga 29\% $( \pm 10-15 \%$ relative error), P3: Ni 71\%; Ga 29\% ( $\pm 10-15 \%$ relative error).

\section{Catalytic hydrogenation of alkynes}

A Büchi stainless-steel autoclave with a glass inlet was charged with $0.1 \mathrm{~g}$ of a freshly synthesized $\mathrm{NiGa} /[\mathrm{BMIm}]\left[\mathrm{BF}_{4}\right]$ or $\mathrm{Ni} /$ [BMIm] $\left[\mathrm{BF}_{4}\right]$ dispersion $(0.5 \mathrm{wt} \%$ in total metal, $85 \mu \mathrm{mol} \mathrm{Ni}$ or $39 \mu \mathrm{mol} \mathrm{NiGa}) .2 \mathrm{~g}$ of degassed, dry substrate 1-octyne $(2.5 \mathrm{~mL}$, $18.1 \mathrm{mmol}$ ) or phenylacetylene (tolan, $11.2 \mathrm{mmol}$ ) was added. For 1-octyne the NiGa: substrate ratio was $1: 464$ or $\mathrm{Ni}:$ substrate ratio $=1: 212 ; \mathrm{NiGa}:$ tolan $=1: 287, \mathrm{Ni}:$ tolan $=1: 131$. The reaction mixture was heated to $120{ }^{\circ} \mathrm{C}$. After reaching the reaction temperature the autoclave was pressurized with $\mathrm{H}_{2}$ to 5 bar (Büchi press flow gas controller, bpc) which was kept constant by the Büchi bpc. After the chosen time $(3 \mathrm{~h})$ the reaction was stopped, cooled down and a $0.5 \mathrm{~g}$ sample was analyzed for its content by GC/MS and NMR. Conversion and selectivity were determined by GC/MS (Tables S5 and S6 in the $\mathrm{ESI} \dagger$ ) [retention times: 1.51 (1-octene), 1.67 (octane), 1.87 (1-octyne), Shimadzu GC2014, column Ultra2, crosslinked 5\% PhMe silicone, $25 \mathrm{~m} \times 0.2 \mathrm{~mm} \times 11 \mu \mathrm{m}]$. A ${ }^{1} \mathrm{H}$ NMR spectrum was recorded by dissolving $0.1 \mathrm{~mL}$ of the sample in $0.65 \mathrm{~mL}$ deuterated chloroform (see Fig. S21 in the ESI $\dagger$ ).

\section{Acknowledgements}

Authors are thankful to the Deutsche Forschungsgemeinschaft (DFG) for financial support and to Dr. Juri Barthel and the Ernst Ruska-Centre (ER-C) for Microscopy and Spectroscopy with Electrons, Jülich Research Centre and RWTH Aachen University, 52425 Jülich, Germany for help and access to the TEM facilities.

\section{Notes and references}

1 (a) S. Duan and R. Wang, Progress in Natural Science: Materials International, 2013, 23, 113-126, and references in there; (b) G. Krishnan, M. A. Verheijen, G. H. ten Brink, G. Palasantzas and B. J. Kooi, Nanoscale, 2013, 5, 53755383; (c) J. H. Sinfelt, J. Catal., 1973, 29, 308-315; (d) J. H. Sinfelt, Bimetallic Catalysts: Discoveries, Concepts and Applications, Wiley, New York, 1983. 
2 (a) F. Tao, S. Zhang, L. Nguyen and X. Zhang, Chem. Soc. Rev., 2012, 41, 7980-7993; (b) Y. Pei, G. Zhou, N. Luan, B. Zong, M. Qiao and F. Tao, Chem. Soc. Rev., 2012, 41, 81408162.

3 (a) M. Sankar, N. Dimitratos, P. J. Miedziak, P. P. Wells, C. J. Kiely and G. J. Hutchings, Chem. Soc. Rev., 2012, 41, 8099-8139; (b) D. M. Alonso, S. G. Wettstein and J. A. Dumesic, Chem. Soc. Rev., 2012, 41, 8075-8098; (c) R. Ferrando, J. Jellinek and R. L. Johnston, Chem. Rev., 2008, 108, 847-910; (d) M. Fatmi, M. A. Ghebouli, T. Chihi, S. Boucetta and Z. K. Heiba, Rom. J. Phys., 2011, 56, 935-951. 4 (a) J. Zhang, G. Chen, D. Guay, M. Chaker and D. Ma, Nanoscale, 2014, 6, 2125-2130; (b) P. Xi, Y. Cao, F. Yang, C. Ma, F. Chen, S. Yu, S. Wang, Z. Zeng and X. Zhang, Nanoscale, 2013, 5, 6124-6130; (c) F. Nosheen, Z.-C. Zhang, J. Zhuang and X. Wang, Nanoscale, 2013, 5, 3660-3663; (d) Y. Li, Z. W. Wang, C.-Y. Chiu, L. Ruan, W. Yang, Y. Yang, R. E. Palmer and Y. Huang, Nanoscale, 2012, 4, 845-851; (e) J. Liu, L. L. Zhang, J. Zhang, T. Liu and X. S. Zhao, Nanoscale, 2013, 5, 11044-11050; $(f)$ D. Cheng and W. Wang, Nanoscale, 2012, 4, 2408-2415; $(g)$ Z.-C. Zhang, J.-F. Hui, Z.-G. Guo, Q.-Y. Yu, B. Xu, X. Zhang, Z.-C. Liu, C.-M. Xu, J.-S. Gao and X. Wang, Nanoscale, 2012, 4, 26332639; (h) S. Shen, J. Zhuang, Y. Yang and X. Wang, Nanoscale, 2011, 3, 272-279.

5 (a) S. Khanal, N. Bhattarai, J. J. Velázquez-Salazar, D. Bahena, G. Soldano, A. Ponce, M. M. Mariscal, S. Mejía-Rosales and M. José-Yacamán, Nanoscale, 2013, 5, 12456-12463; (b) P. Lara, O. R. Wheelaghan, S. Conejero, R. Poteau, K. Philippot and B. Chaudret, Angew. Chem., Int. Ed., 2011, 50, 12080-12084; (c) T. C. Golindano, S. I. Martínez, O. Z. Delgado and G. P. Rivas, Nanotechnology, 2005, 2, 634-637; (d) N. Cordente, C. Amiens, B. Chaudret, M. Respaud and F. Senocq, J. Appl. Phys., 2003, 94, 63586365; (e) Y. Li, J. Liu, Y. Wang and Z. L. Wang, Chem. Mater., 2001, 13, 1008-1014.

6 B. Cormary, F. Dumestre, N. Liakakos, K. Soulantica and B. Chaudret, Dalton Trans., 2013, 42, 12546-12553.

7 (a) M. V. Kovalenko and C. Coperet, Dalton Trans., 2013, 42, 12520; (b) Ö. Metin, X. Sun and S. Sun, Nanoscale, 2013, 5, 910-912; (c) C. Kumara and A. Dass, Nanoscale, 2012, 4, 4084-4086; (d) Z.-C. Zhang, J.-F. Hui, Z.-G. Guo, Q.-Y. Yu, B. Xu, X. Zhang, Z.-C. Liu, C.-M. Xu, J.-S. Gao and X. Wang, Nanoscale, 2012, 4, 2633-2639; (e) C. Kumara and A. Dass, Nanoscale, 2011, 3, 3064-3067.

8 (a) M. Armbrüster, K. Kovnir, M. Behrens, D. Teschner, Y. Grin and R. Schlögl, J. Am. Chem. Soc., 2010, 132, 1474514747; (b) M. Armbrüster, G. Wowsnick, M. Friedrich, M. Heggen and R. Cardoso-Gil, J. Am. Chem. Soc., 2011, 133, 9112-9118; (c) A. Ota, M. Armbrüster, M. Behrens, D. Rosenthal, M. Friedrich, I. Kasatkin and F. Girgsdies, J. Phys. Chem. C, 2011, 115, 1368-1374; (d) M. Friedrich, D. Teschner, A. Knop-Gericke and M. Armbrüster, J. Catal., 2012, 285, 41-47; (e) K. Kovnir, M. Armbrüster, D. Teschner, T. Venkov, L. Szentmiklósi, F. C. Jentoft, A. Knop-Gericke, Yu. Grin and R. Schlögl, Surface Sci., 2009, 603, 1784-1792; (f) J. Osswald, K. Kovnir,
M. Armbrüster, R. Giedigkeit, J. E. Jentoft, U. Wild, Y. Grin and R. Schlögl, J. Catal., 2008, 258, 219-227.

9 M. Armbrüster, K. Kovnir, M. Friedrich, D. Teschner, G. Wowsnick, M. Hahne, P. Gille, L. Szentmiklósi, M. Feuerbacher, M. Heggen, F. Girgsdies, D. Rosenthal, R. Schlögl and Yu. Grin, Nat. Mater., 2012, 11, 690-693.

10 (a) B. Bridier, J. Pérez-Ramírez, A. Knop-Gericke, R. Schlögl and D. Teschner, Chem. Sci., 2011, 2, 1379-1383; (b) B. Bridier and J. Pérez-Ramírez, J. Am. Chem. Soc., 2010, 132, 4321-4327.

11 (a) H. Arnold, F. Döbert and J. Gaube, in Handbook of Heterogeneous Catalysis, ed. G. Ertl, H. Knözinger and J. Weitkamp, VCH, Weinheim, 1997, p. 2165; (b) A. Borodzinski, Catal. Rev., 2006, 48, 91-144; (c) A. Borodzinski and G. C. Bond, Catal. Rev., 2008, 50, 379469.

12 S. Dominguez-Dominguez, A. Berenguer-Murcia, D. CazorlaAmoros and A. Linares-Solano, J. Catal., 2006, 243, 74-81.

13 (a) M. P. Conley, R. M. Drost, M. Baffert, D. Gajan, C. Elsevier, W. T. Franks, H. Oschkinat, L. Vyre, A. Zagdoun, A. Rossini, M. Lelli, A. Lesage, G. Casano, O. Ouari, P. Tordo, L. Emsley, C. Copéret and C. Thieuleux, Chem.-Eur. J., 2013, 19, 12234-12238; (b) T. Mitsudome, Y. Takahashi, S. Ichikawa, T. Mizugaki, K. Jitsukawa and K. Kaneda, Angew. Chem., Int. Ed., 2013, 52, 1481-1485; (c) P. Zhang, J. Yuan, T.-P. Fellinger, M. Antonietti, H. Li and Y. Wang, Angew. Chem., Int. Ed., 2013, 52, 6028-6032; (d) A. Yarulin, I. Yuranov, F. Cardenas-Lizana, P. Abdulkin and L. Kiwi-Minsker, J. Phys. Chem. C, 2013, 117, 13424-13434; (e) D. Deng, Y. Yang, Y. Gong, Y. Li, X. Xu and Y. Wang, Green Chem., 2013, 15, 2525-2531.

14 P. T. Witte, S. Boland, F. Kirby, R. van Maanen, B. F. Bleeker, D. A. Matthijs de Winter, J. A. Post, J. W. Geus and P. H. Berben, ChemCatChem, 2013, 5, 582-587.

15 G. A. Attard, J. A. Bennett, I. Mikheenko, P. Jenkins, S. Guan, S. L. E. Macaskie, J. Wood and A. J. Wain, Faraday Discuss, 2013, 162, 57-75.

16 M. Niu, Y. Wang, W. Li, J. Jiang and Z. Jin, Catal. Commun., 2013, 38, 77-81.

17 D. Köhler, M. Heise, A. I. Baranov, Y. Luo, D. Geiger, M. Ruck and M. Armbrüster, Chem. Mater., 2012, 24, 1639-1644.

18 M. Yan, T. Jin, Y. Ishikawa, T. Minato, T. Fujita, L.-Y. Chen, M. Bao, N. Asao, M.-W. Chen and Y. Yamamoto, J. Am. Chem. Soc., 2012, 134, 17536-17542.

19 (a) D. Mei, M. Neurock and C. M. Smith, J. Catal., 2009, 268, 181-195; (b) Y. Jin, A. K. Datye, E. Rightor, R. Gulotty, W. Waterman, M. Smith, M. Holbrook, J. Maj and J. Blackson, J. Catal., 2001, 203, 292-306; (c) N. A. Khan, S. Shaikhutdinov and H.-J. Freund, Catal. Lett., 2006, 108, 159-163.

20 W. M. H. Sachtler, Catal. Rev.: Sci. Eng., 1976, 14, 193-197. 21 D. Teschner, J. Borsodi, A. Wootsch, Z. Révay, M. Hävecker, A. Knop-Gericke, S. D. David Jackson and R. Schlögl, Science, 2008, 320, 86-89.

22 M. Cokoja, H. Parala, M. K. Schröter, A. Birkner, M. W. E. van den Berg, K. V. Klementiev, W. Grünert and R. A. Fischer, J. Mater. Chem., 2006, 16, 2420-2428. 
23 K. Schütte, H. Meyer, C. Gemel, J. Barthel, R. A. Fischer and C. Janiak, Nanoscale, 2014, 6, 3116-3126.

24 (a) M. Cokoja, H. Parala, A. Birkner, O. Shekhah, M. W. E. van den Berg and R. A. Fischer, Chem. Mater., 2007, 19, 5721-5733; (b) M. Cokoja, H. Parala, A. Birkner, R. A. Fischer, O. Margeat, D. Ciuculescu, C. Amiens, B. Chaudret, A. Falqui and P. Lecante, Eur. J. Inorg. Chem., 2010, 1599-1603; (c) M. Cokoja, PhD thesis, Ruhr University Bochum, Germany, 2007; (d) A. Doddi, PhD thesis, Ruhr University Bochum, 2012.

25 (a) V. I. Pârvulescu and C. Hardacre, Chem. Rev., 2007, 107, 2615-2665; (b) J. D. Scholten, B. C. Leal and J. Dupont, ACS Catal., 2012, 2, 184-200.

26 (a) E. Redel, M. Walter, R. Thomann, L. Hussein, M. Krüger and C. Janiak, Chem. Commun., 2010, 46, 1159-1161; (b) E. Redel, M. Walter, R. Thomann, C. Vollmer, L. Hussein, H. Scherer, M. Krüger and C. Janiak, Chem.-Eur. J., 2009, 15, 10047-10059; (c) E. Redel, R. Thomann and C. Janiak, Inorg. Chem., 2008, 47, 14-16.

27 (a) G. S. Fonseca, G. Machado, S. R. Teixeira, G. H. Fecher, J. Morais, M. C. M. Alves and J. Dupont, J. Colloid Interface Sci., 2006, 301, 193-204; (b) G. S. Fonseca, J. B. Domingos, F. Nome and J. Dupont, J. Mol. Catal. A: Chem., 2006, 248, 10-16; (c) G. S. Fonseca, A. P. Umpierre, P. F. P. Fichtner, S. R. Teixeira and J. Dupont, Chem.-Eur. J., 2003, 9, 32633269; (d) J. Dupont, G. S. Fonseca, A. P. Umpierre, P. F. P. Fichter and S. R. Teixeira, J. Am. Chem. Soc., 2002, 124, 4228-4229.

28 (a) P. Arquillière, P. H. Haumesser and C. C. Santini, Microelectron. Eng., 2012, 92, 149-151; (b) E. T. Silveira, A. P. Umpierre, L. M. Rossi, G. Machado, J. Morais, G. V. Soares, I. J. R. Baumvol, S. R. Teixeira, P. F. P. Fichtner and J. Dupont, Chem.-Eur. J., 2004, 10, 3734-3740.

29 P. Migowski, G. Machado, S. R. Teixeira, M. C. M. Alves, J. Morais, A. Traverse and J. Dupont, Phys. Chem. Chem. Phys., 2007, 9, 4814-4821.

30 (a) D. Marquardt, J. Barthel, M. Braun, C. Ganter and C. Janiak, CrystEngComm, 2012, 14, 7607-7615; (b) G. Salas, A. Podgorsek, P. S. Campbell, C. C. Santini, A. A. H. Pádua, M. F. Costa Gomes, K. Philippot, B. Chaudret and M. Turmine, Phys. Chem. Chem. Phys., 2011, 13, 1352713536; (c) T. Gutel, J. Garcia-Antón, K. Pelzer, K. Philippot, C. C. Santini, Y. Chauvin, B. Chaudret and J.-M. Basset, J. Mater. Chem., 2007, 17, 3290-3292.

31 P. S. Campbell, M. H. G. Prechtl, C. C. Santini and P.-H. Haumesser, Curr. Org. Chem., 2013, 17, 414-429.

32 (a) C. Vollmer and C. Janiak, Coord. Chem. Rev., 2011, 255, 2039-2057; (b) C. Vollmer, M. Schröder, Y. Thomann, R. Thomann and C. Janiak, Appl. Catal., A, 2012, 425-426, 178-183; (c) D. Marquardt, C. Vollmer, R. Thomann, P. Steurer, R. Mülhaupt, E. Redel and C. Janiak, Carbon, 2011, 49, 1326-1332; (d) D. Marquardt, Z. Xie, A. Taubert, R. Thomann and C. Janiak, Dalton Trans., 2011, 40, 82908293; (e) C. Vollmer, E. Redel, K. Abu-Shandi, R. Thomann, H. Manyar, C. Hardacre and C. Janiak, Chem.-Eur. J., 2010, 16, 3849-3858; $(f)$ E. Redel, J. Krämer, R. Thomann and
C. Janiak, J. Organomet. Chem., 2009, 694, 1069-1075; $(g)$ J. Krämer, E. Redel, R. Thomann and C. Janiak, Organometallics, 2008, 27, 1976-1978; (h) E. Redel, R. Thomann and C. Janiak, Chem. Commun., 2008, 17891791.

33 (a) C. Janiak, Z. Naturforsch., B: J. Chem. Sci., 2013, 68, 10591089; (b) D. Marquardt and C. Janiak, Nachr. Chem., 2013, 61, 754-757.

34 (a) L. S. Hsu, K. L. Tsang and S. C. Chung, Mater. Res. Soc. Symp. Proc., 1996, 437, 53-58; (b) S. Y. Lee and P. Nash, GaNi (Gallium-Nickel), Phase Diagrams of Binary Nickel Alloys, ed. P. Nash, ASM International, Materials Park, OH, 1991, pp. 133-140; (c) T. Ikeda, Y. Nose, T. Korata, H. Numakura and M. Koiwa, J. Phase Equilib. Diffus., 1999, 20, 626-630; (d) R. Ducher, R. Kainuma and K. Ishida, Intermetallics, 2007, 15, 148-153; (e) C. Schmetterer, H. Flandorfer, C. L. Lengauer, J. P. Bros and H. Ipser, Intermetallics, 2010, 18, 277-285; (f) M. F. Singleton and P. Nash, Bull. Alloy Phase Diagrams, 1988, 9, 592-597; (g) P. Waldner and H. Ipser, Z. Metallkd., 2002, 93, 825-832; (h) H. Okamoto, J. Phase Equilib. Diffus., 2003, 24, 379.

35 (a) K. P. Gupta, J. Phase Equilib. Diffus., 2008, 29, 101-109; (b) H. Okamoto, J. Phase Equilib. Diffus., 2010, 31, 575-576; (c) H. Okamoto, J. Phase Equilib. Diffus., 2008, 29, 296.

36 (a) A. Pramanick and X.-L. Wang, JOM, 2013, 65, 54-64; (b) A. Backen, S. R. Yeduru, A. Diestel, L. Schultz, M. Kohl and S. Faehler, Adv. Eng. Mater., 2012, 14, 696-709; (c) K. V. Peruman and M. Mahendran, Pure Appl. Chem., 2011, 83, 2071-2077; (d) K. V. Peruman, M. Mahendran, S. Seenithurai, R. Chokkalingam, R. K. Singh and V. Chandrasekaran, J. Phys. Chem. Solids, 2010, 71, 15401544.

37 (a) L.-S. Hsu, Y. D. Yao and Y. Y. Chen, Mod. Phys. Lett. B., 1997, 11, 407-414; (b) J. A. Leiro and M. H. Heinonen, Surf. Sci., 1996, 346, 73-78; (c) L. S. Hsu and R. S. Williams, J. Phys. Chem. Solids, 1994, 55, 305-312; (d) T. J. Bastow and G. W. West, J. Phys.: Condens. Matter, 2003, 15, 83898406.

38 (a) P. Lara, O. R. Wheelaghan, S. Conejero, R. Poteau, K. Philippot and B. Chaudret, Angew. Chem., Int. Ed., 2011, 50, 12080-12084; (b) T. C. Golindano, S. I. Martínez, O. Z. Delgado and G. P. Rivas, Nanotechnology, 2005, 2, 634-637; (c) N. Cordente, C. Amiens, B. Chaudret, M. Respaud and F. Senocq, J. Appl. Phys., 2003, 94, 63586365.

39 (a) J. D. Makinson, J. S. Lee, S. H. Magner, R. J. De Angelis, W. N. Weins and A. S. Hieronymus, Adv. X-Ray Anal., 2000, 42, 407-411; (b) F. Zhang, S.-W. Chan, J. E. Spanier, E. Apak, Q. Jin, R. D. Robinson and I. P. Herman, Appl. Phys. Lett., 2002, 80, 127-129; (c) K. M. Reddy, S. V. Manorama and A. R. Reddy, Mater. Chem. Phys., 2002, 78, 239-245.

40 M. Molon, T. Bollermann, C. Gemel, J. Schaumann and R. A. Fischer, Dalton Trans., 2011, 40, 10769-10774.

41 L. S. Meriwether and M. L. Fiene, J. Am. Chem. Soc., 1959, 81, 4200-4208.

42 T. Welton, Chem. Rev., 1999, 99, 2071-2084. 
43 J. P. Hallett and T. Welton, Chem. Rev., 2011, 111, 35083576.

44 (a) T. Torimoto, T. Tsuda, K. Okazaki and S. Kuwabata, Adv. Mater., 2010, 22, 1196-1221; (b) C. Feldmann, $Z$. Naturforsch., B: J. Chem. Sci., 2013, 68, 1057.

45 D. Freudenmann, S. Wolf, M. Wolff and C. Feldmann, Angew. Chem., Int. Ed., 2011, 50, 11050-11060.

46 (a) E. Ahmed, J. Breternitz, M. F. Groh and M. Ruck, CrystEngComm, 2012, 14, 4874-4885; (b) E. Ahmed and M. Ruck, Dalton Trans., 2011, 40, 9347-9357; (c) M. F. Groh, U. Müller, E. Ahmed, A. Rothenberger and M. Ruck, Z. Naturforsch., B: J. Chem. Sci., 2013, 68, 11081122.

47 R. E. Morris, Chem. Commun., 2009, 2990-2998.

48 E. R. Parnham and R. E. Morris, Acc. Chem. Res., 2007, 40, 1005-1013.

49 J. Dupont and J. D. Scholten, Chem. Soc. Rev., 2010, 39, 17801804.

50 Y. Lin and S. Dehnen, Inorg. Chem., 2011, 50, 7913-7915.

51 P. Lodge, Science, 2008, 321, 50.

52 M. Larhed, C. Moberg and A. Hallberg, Acc. Chem. Res., 2002, 35, 717-727.

53 M. F. Groh, M. Heise, M. Kaiser and M. Ruck, Nachr. Chem., 2013, 61, 26-29.

54 A. L. Buchachenko and E. L. Frankevich, Chemical Generation and Reception of Radio- and Microwaves, Wiley-VCH, Weinheim, Germany, 1993, pp. 41-56.
55 V. K. Ahluwulia, Alternative Energy Processes in Chemical Synthesis, Alpha Science International LTD, Oxford, United Kingdom, 2008.

56 I. Bilecka and M. Niederberger, Nanoscale, 2010, 2, 1358-1374.

57 J. I. Langford and A. J. C. Wilson, J. Appl. Crystallogr., 1978, 11, 102-113.

58 M. Cokoja, H. Parala, M. K. Schroter, A. Birkner, M. W. E. van den Berg, W. Grunert and R. A. Fischer, Chem. Mater., 2006, 18, 1634-1642.

59 J. D. Scholten, G. Ebeling and J. Dupont, Dalton Trans., 2007, 5554-5560.

60 T. Cadenbach, C. Gemel, R. Schmid, M. Halbherr, K. Yusenko, M. Cokoja and R. A. Fischer, Angew. Chem., Int. Ed., 2009, 48, 3872-3876.

61 M. Treguer, C. de Cointet, H. Remita, J. Khatouri, M. Mostafavi, J. Amblard and J. Belloni, J. Phys. Chem. B, 1998, 102, 4310-4321.

62 (a) F. Alonso, I. Osante and M. Yus, Tetrahedron, 2006, 63, 93-102; (b) F. Alonso, I. Osante and M. Yus, Adv. Synth. Catal., 2006, 348, 305-308.

63 T. Steinke, M. Cokoja, C. Gemel, A. Kempter, A. Krapp, G. Frenking, U. Zenneck and R. A. Fischer, Angew. Chem., Int. Ed., 2005, 44, 2943-2946.

64 D. J. Krysan and P. B. Mackenzie, J. Org. Chem., 1990, 55, 4229-4230.

65 (a) P. Jutzi, B. Neumann, G. Reumann and H. G. Stammler, Organometallics, 1998, 17, 1305-1314; (b) P. Jutzi and L. O. Schebaum, J. Organomet. Chem., 2002, 654, 176-179. 